\title{
Fungal biosurfactants, from nature to biotechnological product: bioprospection, production and potential applications
}

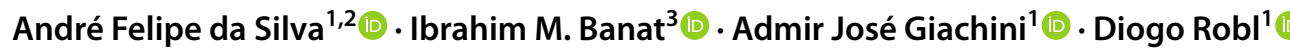

Received: 15 March 2021 / Accepted: 1 June 2021 / Published online: 16 June 2021

(c) The Author(s), under exclusive licence to Springer-Verlag GmbH Germany, part of Springer Nature 2021

\begin{abstract}
Biosurfactants are in demand by the global market as natural commodities that can be added to commercial products or use in environmental applications. These biomolecules reduce the surface/interfacial tension between fluid phases and exhibit superior stability to chemical surfactants under different physico-chemical conditions. Biotechnological production of biosurfactants is still emerging. Fungi are promising producers of these molecules with unique chemical structures, such as sophorolipids, mannosylerythritol lipids, cellobiose lipids, xylolipids, polyol lipids and hydrophobins. In this review, we aimed to contextualize concepts related to fungal biosurfactant production and its application in industry and the environment. Concepts related to the thermodynamic and physico-chemical properties of biosurfactants are presented, which allows detailed analysis of their structural and application. Promising niches for isolating biosurfactant-producing fungi are presented, as well as screening methodologies are discussed. Finally, strategies related to process parameters and variables, simultaneous production, process optimization through statistical and genetic tools, downstream processing and some aspects of commercial products formulations are presented.
\end{abstract}

Keywords Filamentous fungi $\cdot$ Yeasts $\cdot$ Biosurfactants $\cdot$ Bioprocess $\cdot$ Screening $\cdot$ Downstream

$\begin{array}{lll}\text { Abbreviations } & & \mathrm{EI}_{24} \\ \text { CMC } & \text { Critical micellar concentration } & \text { MATH } \\ \text { EPS } & \text { Exopolysaccharides } & \\ \text { SL } & \text { Sophorolipid } & \text { PUM } \\ \text { MEL } & \text { Mannosylerythritol lipids } & \\ \text { TL } & \text { Trehalose lipids } & \text { CTAB } \\ \text { XLs } & \text { Xylolipids } & \text { YMG } \\ \text { CL } & \text { Cellobiose lipids } & \\ \text { PL } & \text { Polyol lipids } & \text { TG } \\ \text { LM } & \text { Liamocins } & \text { C/N } \\ \text { PEFA } & \text { Polyol fatty acid esters } & \\ \text { LPP } & \text { Lipopeptides } & \text { STR } \\ \text { ITS } & \text { Internal transcribed spacer } & \text { vvm }\end{array}$

Diogo Robl

diogo.robl@ufsc.br

1 Department of Microbiology, Immunology and Parasitology, Federal University of Santa Catarina (UFSC), Florianópolis, SC, Brazil

2 Bioprocess and Biotechnology Engineering Undergraduate Program, Federal University of Tocantins (UFT), Gurupi, TO, Brazil

3 School of Biomedical Sciences, Faculty of Life and Health Sciences, Ulster University, Coleraine, UK
Emulsification index

Microbial adhesion to hydrocarbon test

Buffer solution composed of phosphate, urea, magnesium

Cetyltrimethylammonium Bromide

Culture medium composed of yeast, malt and glucose

Triacylglycerols

Ratio between the quantity of carbon and nitrogen sources

Stirred tank reactor

Volumetric air flow $\times$ volume of half $\times$ minute $^{-1}$

TLC Thin layer chromatography

FTIR Fourier transform infrared

NMR Nuclear magnetic resonance

MS Mass spectrometry

GC Gas chromatography

GC-MS Mass spectrometry coupled to gas chromatography 
HPLC

High-performance liquid

chromatography

MALDI-TOF-MS Matrix-assisted laser desorp-

tion ionization time of light mass

spectrometry

\section{Introduction}

Since the 1930s, chemical surfactants have been part of several commercial products. These molecules are structurally composed of a hydrophilic and a hydrophobic moiety, with variations in structure, which allows for applications in numerous environmental and industrial areas [1,2]. Main physico-chemical action of surfactants is to reduce the surface and interfacial tension at the interfaces between immiscible liquids, solids and gases, allowing distinct phases to mix and interact $[1,3]$. They play a diverse and significant role in various industrial market segments, including products currently in demand due to the COVID-19 pandemic $[4,5]$. Several products contain a significant amount of surfactants in their composition, such as toothpastes, soaps, detergents, fabric softeners, etc. [3]. Most of the chemical surfactants are synthesized from petrochemicals products, which although economically viable, are ecologically undesirable $[1,3]$. However, biotechnology and chemical companies are continuously engaged in research for safer and more environmentally friendly industrial bioprocesses preferably using ecological biomolecules with superior structural and functional properties [6, 7]. In this context, biosurfactants represent a sustainable alternative to these requirements, since they are naturally synthesized by biological systems such as plants and microorganisms, offering lower toxicity and higher degradability $[6,8,9]$.

Bacterial biosurfactants (glycolipids, glycoproteins, lipopeptides) are produced by different strains mainly Pseudomonas and Bacillus strains, leading the largest volume of data and scientific output [10]. Fungal biosurfactants, in comparison, represent only $19 \%$ out of the total (12\% from ascomycetes and $7 \%$ from basidiomycetes), while having the widest chemical structural variant of biosurfactants, some of these are produced exclusively by fungi, like sophorolipids, mannosylerythritol lipids, cellobiose lipids, xylolipids, lipid polyols and hydrophobins [11-13]. In general, fungal biosurfactants have chemical structures versatility and their properties allow a wide range of applications such as in personal care sector [14], food [15], agriculture [16], pharmaceutical [17], biomedicine [18], materials engineering [19], bioenergies [20] and environmental remediation [21, 22].

Both bacterial and fungal biosurfactant production is still quite restricted, due to the production and recovery costs that often are higher than chemical surfactants and the fact that most bioprocesses show low yield and productivity [23].
In summary, industrial biotechnology can minimize limitations inherent to each stage, including isolation, screening, growth and product yield optimization, downstream processing, recovery, purification and characterization of the products [24]. In this context, after the isolation of the fungal strain from different environments, several techniques based on direct and indirect measurement of surface tension and/ or emulsifying activity can be applied to select producing strains [25]. In addition, the use of agro-industrial waste, non-conventional substrates and the optimization of bioprocess parameters through statistical designs have also been shown as a tool to enhance the viability of the production of these biomolecules [26, 27]. Downstream processing steps are also constantly being improved to ensure greater yields and better performance and to elucidate structural variants of these molecule $[28,29]$.

The purpose of this review is to collate information related to fungal biosurfactants and bioemulsifiers and determine the main types and properties of these molecules. The review evaluates the bioprocesses involved in biosurfactants production considering the entire innovation chain, from isolation sources and selection tests for producing microorganisms, cultivation parameters, process optimization through statistical and genetic tools, to downstream processing; in addition to their potential in formulating commercial products.

\section{Structural classes, properties and applications}

The versatility of the chemical structures of fungal biosurfactants is directly correlated to their biochemical composition and molecular weight, these macromolecules carryout physico-chemical and biological properties of biotechnological interest. Low molecular weight biosurfactants have their molar mass ranging between 0.5 and $1.5 \mathrm{kDa}$ [30], while bioemulsifiers (high molecular weight) also known as Exopolysaccharides (EPS) can reach up to $500 \mathrm{kDa}$ [31-33]. Figure 1 presents a schematic chart for understanding the action of biosurfactants and bioemulsifiers.

In summary, the main function of surfactants is to decrease the tension at the fluid interfaces (liquid/liquid [emulsion] and liquid/air [foam]). Likewise, emulsifiers promote the formation of emulsions and steric stabilization at the interfaces of small drops of emulsions and foams, providing long-term stability [37]. It is known that some biomolecules have both properties, surfactants and emulsifiers [38]. Biosurfactant types include glycolipids, polyol lipids, proteins, carbohydrate-lipid-protein complexes, lipoproteins (or lipopeptides) and glycoproteins [12, 39].

Figure 2 shows the classes of fungal biosurfactant glycolipids (low molecular weight) and polyol lipids based on 


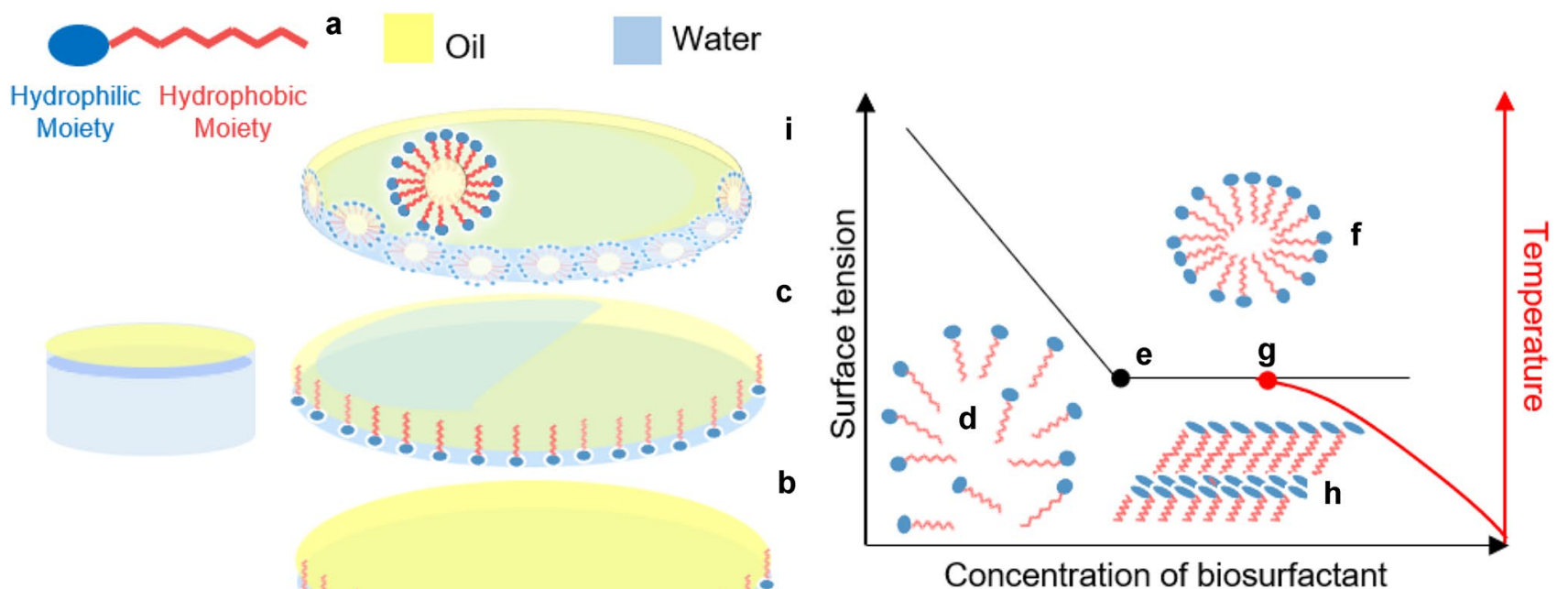

Fig. 1 Biosurfactants are amphiphilic molecules, their composition consists of hydrophilic (carboxylic acids, alcohols, amino acids, phosphates, peptides, mono-, di- or polysaccharide cations or anions) and hydrophobic (hydrocarbon chains or saturated/unsaturated fatty acids) moieties (a). These molecules accumulate at phase interfaces of different polarities and stabilise heterogeneous phases (oil/air bubble droplets). b Thus, adsorption reduces the free energy per unit area needed to create a new surface, a reduction that is closely related to surface tension (liquid-air) and interfacial tension (liquid-liquid)

their composition and chemical structure. Table 1 presents the classes of high molecular fungal biosurfactants based on their biochemical composition, structural characteristics and main producing microorganisms reported.

\section{Sophorolipids}

Among fungal glycolipids, Sophorolipids (SL) has taken the lead industrially due to its high production yields, which can exceed $300 \mathrm{gL}^{-1}$ and ample applicability in the industrial, environmental and health sectors [52]. SL has a hydrophilic portion of sophorose, a two $\beta-1,2$ glucose residues linked to a hydrophobic long fatty acid chain $\left(\mathrm{C}_{16}\right.$ or $\left.\mathrm{C}_{18}\right)$, terminally or subterminally hydroxylated (Fig. 2a). SL are synthesized metabolically in two main forms, lactonic or acidic, that lead to a mixture of different congeners and quantities in the final production lines [53,54]. Acidic SL are alicyclic and have a carboxylic acid group $(\mathrm{COOH})$ at the end of the hydrophobic portion, while lactonic SL are cyclic with ester functionality $[55,56]$.

Although 20 or more congeners can occur of SL, generally a few forms are dominant [57]. The structures of SL can be modified through chemicals or enzymes [58], i.e., the combination of genetic manipulation techniques allows the modification in the hydrophilic and/or hydrophobic portions of the molecule [9]. The structural variation is due to the [note the displacement of surface oil over water in c] [34]. Biosurfactant monomers (d) due to their self-assembly properties on reaching the Critical Micellar Concentration (CMC) (e), can form aggregated micellar structures (f) [35]. Micelle formation and solubility occur just above the Krafft temperature (g), i.e., the critical temperature at which micellar self-assembly occurs due to dissolution of the hydrated surfactant crystals (h) [36]. Bioemulsifiers are less effective in reducing surface tension and are involved in the formation and stabilization of emulsions between two immiscible phases (i) $[31,32]$

length and saturation of the fatty acid portion and acetylation of the sophorose, as well as the position of the hydroxyl group in both the lipid portion and the carbohydrate that is esterified with fatty alcohol $[55,59]$.

SL production occurs in several non-pathogenic yeasts, principally from Starmerella genus, which was previously classified as Candida and/or Torulopsis [60]. The diversity of species able to produce SL in this genus explains the SL production with different physico-chemical characteristics, since they have enzymes necessary to synthesize them when grown on hydrophobic substrates, forming fatty acids to be metabolized by $\beta$-oxidation [61].

The SL congeners profile produced by a microorganism can have different types and extensions of bioactivity, therefore, the use of purified SL does not attribute to it an unambiguous activity [62]. Recently, it was reported that the interfacial properties of acidic SL, such as leaching and chelating action, are $\mathrm{pH}$ dependent and can promote its application in hydrometallurgical extraction of metals and separation of ions and minerals through foam flotation, respectively [63]. Lactonic SL in comparison have lower CMC than acidic forms, being more hydrophobic and less soluble in water molecules [54], in the same way that acetylation decreases SL solubility [64]. In addition, lactonic SL have a better surface tension reduction compared to acid SL. However, both have recognized antimicrobial activity [65] and have already 


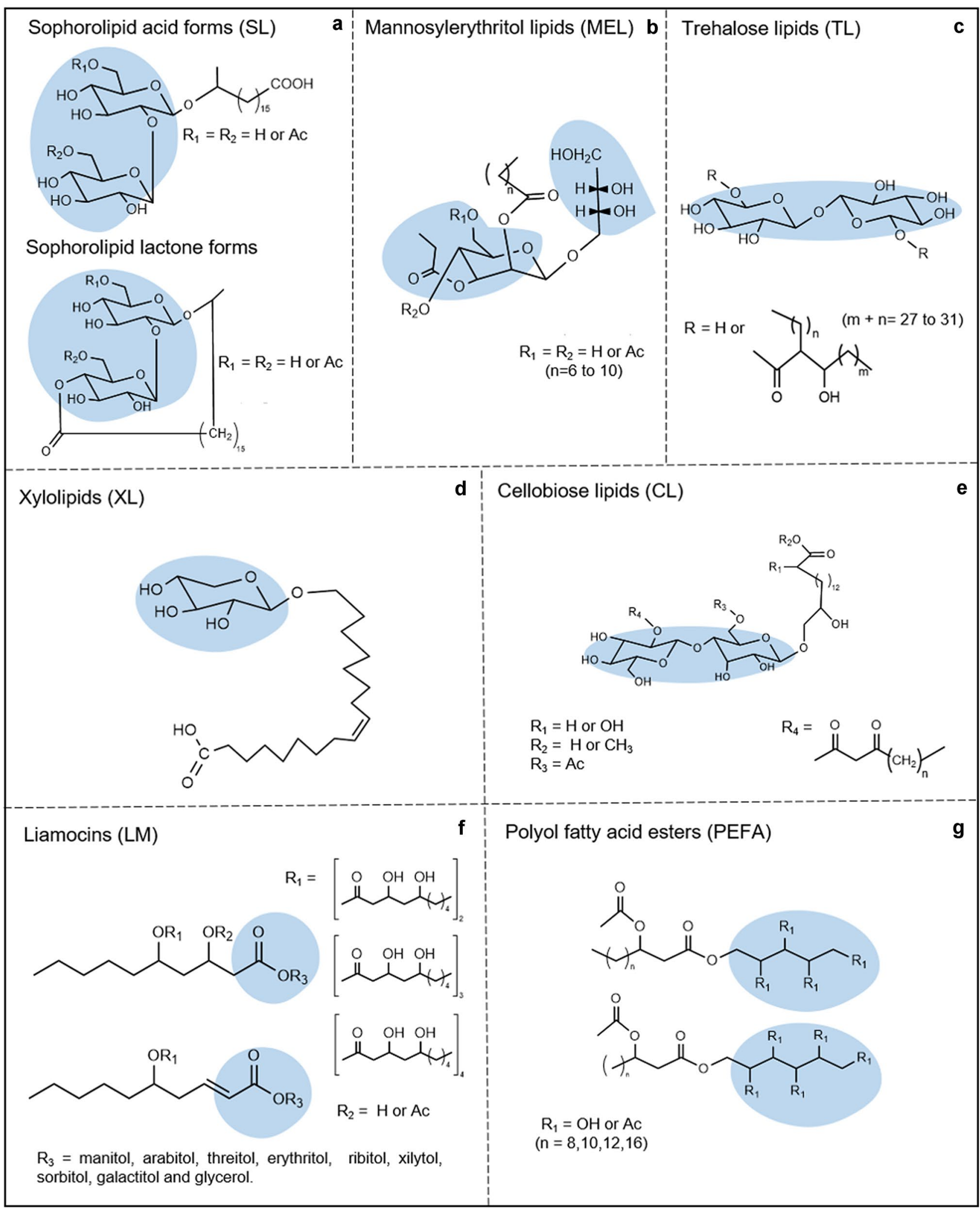

Fig. 2 Chemical structure of fungal glycolipids and polyol lipids (adapted from [12] and [39]). The hydrophilic portions are highlighted in blue 
Table 1 Main high molecular weight fungal biosurfactants

\begin{tabular}{|c|c|c|c|c|}
\hline Group & Biosurfactant & Composition & Producer microorganism & References \\
\hline \multirow[t]{4}{*}{$\begin{array}{l}\text { Carbohydrate-lipid-protein com- } \\
\text { plexes }\end{array}$} & \multirow[t]{4}{*}{ Not classified } & \multirow[t]{4}{*}{$\begin{array}{l}\text { Molecules composed by the ligation } \\
\text { of congeners of carbohydrates, } \\
\text { lipids and proteins }\end{array}$} & $\begin{array}{l}\text { Galactomyces pseudocandidum, } \\
\text { Candida tropicalis and Geotrichum } \\
\text { candidum }\end{array}$ & {$[40]$} \\
\hline & & & Aspergillus flavus & {$[41]$} \\
\hline & & & Penicillium citrinum & {$[42]$} \\
\hline & & & Aspergillus ustus & {$[43]$} \\
\hline \multirow[t]{4}{*}{ Lipopeptides (or lipoproteins) } & \multirow[t]{4}{*}{ Not classified } & \multirow{4}{*}{$\begin{array}{l}\text { Molecules composed of proteins and } \\
\text { lipids }\end{array}$} & Yarrowia lipolytica MTCC9520 & [44] \\
\hline & & & Penicillium chrysogenum SNP5 & {$[45]$} \\
\hline & & & Aspergillus mulundensis & {$[46]$} \\
\hline & & & Fusarium sp. & {$[47]$} \\
\hline \multirow[t]{4}{*}{ Polymeric-Glycoproteins } & Liposan & $\begin{array}{l}\text { Molecule composed of polysaccha- } \\
\text { ride and protein }\end{array}$ & Y. lipolytica & {$[48]$} \\
\hline & \multirow[t]{2}{*}{ Manoproteins } & \multirow{2}{*}{$\begin{array}{l}\text { Mannose polymers covalently linked } \\
\text { to the backbone main protein }\end{array}$} & Saccharomyces cerevisiae, & {$[49]$} \\
\hline & & & Kluyveromyces marxianus & {$[50]$} \\
\hline & Yasan & $\begin{array}{l}\text { Low-lipid polysaccharide-protein } \\
\text { complex }\end{array}$ & Y. lipolytica & {$[51]$} \\
\hline
\end{tabular}

been proven to be prominent compounds with antimicrobial action in topical creams and for oral hygiene [56, 66].

In general, SL have broad antimicrobial activity against several bacterial (Escherichia coli, Pseudomonas aeruginosa, Staphylococcus aureus) [67-69] and fungal pathogens (Colletotrichum gloeosporioides, Fusarium verticilliodes, Fusarium oxysporum, Corynespora cassiicola and Trichophyton rubrum) [70, 71]. In addition, SL have antimicrobial action against Clostridium perfringens and Campylobacter jejuni and their association with lactic acid is a promising natural disinfectant in the poultry industry [72].

In addition to antimicrobial activity, when sophorolipids was added to the bioactive films composed of polylactic acid for food, it enhanced their thermomechanical properties [73]. In this context, SL are promising ingredients in the food industry as they also have emulsifying properties over edible oils and are stable at a wide range of $\mathrm{pH}$, temperature and salinity [74]. Candida albicans SC5314 and Candida glabrata CBS138 sophorolipids have been reported to have emulsifying activities in olive oil, soy oil, almond oils and mustard by $40-50 \%$ [75]. In addition, SLs have sensory properties on the palate and responses induced in human taste buds cell cultures, enabling their application to modulate the taste of food and drugs [76].

Applied as adjuvants in antibiotic recovery processes (erythromycin and amoxicillin), SLs are alternatives for increasing the solubility and transferring to the organic phase through the formation of reverse micelles, in a liquid-liquid extraction processes [17]. SL were also used to remove tetracycline $(88.2 \%)$, sulfadiazine $(96.6 \%)$ and roxithromycin $(100 \%)$ from soils contaminated by these antibiotics [21].
In agriculture, the addition of SL as adjuvants in pesticide formulations resulted in the US patent 2017/0094968 A1, which describes strategies on the use of SL to increase yield in the production of plants of agricultural interest [77]. SLs are also employed at preferably $100-500 \mathrm{~g} / \mathrm{ha}$, allowing a better formation of total biomass or improving harvestable parts in plants [77]. The Medicago sativa and Bidens pilosa plants when grown in soils augmented with SL had an increase in the growth of their shoots and roots, which may have been due to greater microbial activity in the soil after this addition [16].

In materials engineering, SL can be used as stabilizers and reducing/capping agents in the synthesis of metal-based nanomaterials, since they are generally used to improve colloidal stability in water or in aqueous solutions containing salt, many nanoparticles syntheses are carried out in organic media $[78,79]$. SL use in the synthesis of copper $(\mathrm{Cu})$ nanowires through hydrothermal synthesis, together with these nanomaterials, showed the potential for the substitution of components in transparent conductive electrodes [19].

The increase in the yield of enzymatic saccharification applied to vegetable biomass, as in wheat bran (20\%) and steam-exploded wood (67\%) was increased with the addition of SL in enzymatic cocktails, opening applications also aimed at bioethanol production $[20,80]$.

\section{Mannosylerythritol lipids}

The mannosylerythritol lipids (MEL) are composed of 4-O-D-mannopyranosyl-meso-erythritol with various patterns of acylation and acetylation, linked to fatty acid molecules $\left(\mathrm{C}_{8}-\mathrm{C}_{20}\right)$ (Fig. $2 \mathrm{~b}$ ). Their structure may vary with 
the producing microorganism and the substrates used [26]. MEL have an oily appearance and according to the number of acetyl groups and their locations in the mannose, they are characterized as MEL-A (diacetylated in O-4 and O-6), MEL-B (monoacetylated in O-6), MEL-C (monoacetylated at O-4), MEL-D (deacetylated) [81] and MEL-A2 (triacetylated (O-2, O-4 and O-6) [82, 83]. The number of acyl groups in mannose and/or erythritol, and the length of the fatty acid chain, with its levels of saturation, may contribute to differences in several homologues of MEL $[84,85]$. In this way, a detailed characterization of all structures derived from MEL is essential to identify their structure-function relationship and potential application. An MEL variant, with greater hydrophilicity, was identified with the presence of a mannitol instead of an erythritol residue in its structure [86].

MEL are well described for their self-assembling properties (sponge, cube and lamellar) that are influenced by carbohydrate stereochemistry [87]. These structures can form giant vesicles or nanostructures that can be applied as models in the cellular and molecular study processes [39]. MEL production is commonly described from fungi that belong to the Ustilaginales order [88]. Other species, such as Sporisorium sp. aff. sorghi [82], Pseudozyma spp. [28] and Schizonella melanogramma (MEL-A and -B) [89] are also described as MEL producers. As far as we known, the highest MEL $\left(165 \mathrm{gL}^{-1}\right)$ production was obtained in batchfed cultivation of Pseudozyma aphidis [90].

The elucidation of MEL synthesis pathways showed conserved mechanisms, in which a cluster of five conserved genes, including an acetyltransferase gene (matl), a member of the family of the main facilitators $m m f 1$, two acyltransferases ( $\mathrm{macl}$ and $\mathrm{mac} 2$ ) and a glycosyl transferase gene (emt1) are present [91].

The MEL produced by Ustilago hordei differ from those secreted by Ustilago maydis, as they are mostly monoacetylated and contain a different mixture of acyl groups, although the MEL gene clusters of both species show a high degree of synergy (52\%) and similarity (75\%) to the respective genetic products [92]. These differences result from different catalytic activities of matl and macl acylation in the mannosylerythritol fraction at the $\mathrm{C} 2$ position, while mac2 promotes acylation at the $\mathrm{C} 3$ position. This indicates that the elucidation of these enzymes with different substrate specificities [106] may enable a specific MEL production [93].

The production of MEL-D (deacetylated) corresponds to a small fraction compared to other MEL congeners produced during cultivation. As far as it is known, there are no reports of mainly deacetylated MEL production by microorganisms [93]. However, alternative strategies are possible by enzymatic treatment of MEL-B with lipases [94] and genetic modification. The "interruption" of the matl gene in Pseudozyma hubeiensis (MEL-C producer) favours the production of MEL-D [95].
MEL-A produced by the endophytic fungus Ceriporia lacerate are potential adjuncts in environmental bioremediation, and these biomolecules showed a decrease in surface tension $\left(31 \mathrm{mNm}^{-1}\right)$ and emulsifying activity in hydrocarbon contaminants $(78.5 \%)$, soybeans $(76.1 \%)$ and vacuum pump oil (77.4\%) [84]. MEL-B and MEL-C can be applied in the formulation of biopesticides, as they are effective in altering the hydrophobicity of solid surfaces and inhibit germination of Magnaporthe grisea (rice blast) conidia [96].

MEL have excellent interfacial properties and pharmacological actions in drug administration [97], for this purpose MEL-A may be superior to MEL-B/C [81]. The formulation of fungal liposomes coated with chitosan modified with MEL-A can be considered as a promising delivery system, with enhanced antioxidant effects for bioactive compounds [98]. MEL-A have cytostatic activity to trigger apoptosis of B16 cells in vitro [99] and can dramatically increase gene transfection via membrane fusion [100]. In biomedical applications, MEL produced by Ustilago maydis CGMCC 5,203 were used for the synthesis of gold nanoparticles (AuNPs) and demonstrated cytotoxic potential against HepG2 cells [101].

MEL-A and B also showed antimicrobial activity against Gram-positive and Gram-negative bacteria [102], while MEL-A showed antibacterial activity against strains of Micrococcus luteus and S. aureus (FDA209P) and MEL-D against Enterococcus faecalis and E. faecium vancomycinresistant (VRE) strains [103]. In addition, MEL can be used as additives to improve the functional properties of proteins and formulation of edible films for food. These surfactant-protein interactions in food systems ensure consistency, foam capacity and adequate food emulsifying activity [104]. In this sense, MEL addition for active films formulation based on starch provided greater flexibility, permeability to water vapor and hydrophilicity, favouring its use as an edible coating for food and biomedical devices [15].

MEL are also promising molecules for personal care products. Pseudozyma antarctica NBRC 10,736 MEL has been patented as a substitute for skin moisturizers, such as ceramide [105]. MEL-C produced by Pseudozyma hubeiensis have antioxidant effects and superior protective activity (30.3\%) against oxidative stress in human skin cells compared to arbutin (13\%), sunscreen and antioxidants [106]. In addition, MEL can be used as anti-melanogenic agents for effective skin lightening, as they significantly decrease the melanin content in primary normal human melanocytes [14].

\section{Trehalose lipids and xylolipids}

Trehalose lipids (TL) consist of a trehalose disaccharide linked by an ester bond to long-chain fatty acids (Fig. 2c). Only Fusarium fujikuroi was reported to be a TL producer with reducing surface tension $\left(20.08 \mathrm{mNm}^{-1}\right)$. This 
filamentous fungus was isolated from soil samples contaminated with hydrocarbons [107]. TL are present as trehalose dimicolate in bacteria such as mycobacteria, Corynebacterium, Nocardia and Rhodococcus [108]. Most TL are found in these prokaryotes cell walls $[109,110]$, which can make it difficult to extract. In addition, most of these strains can exhibit slow growth and may be pathogenic. Consequently, TL still arouse less industrial interest via biotechnological production [3].

Xylolipids (XLs) on the other hand are composed of xylose monomers linked to fatty acids (Fig. 2d) and are secreted (at a reported $7.48 \mathrm{gL}^{-1}$ ) by Pichia caribbica when grown in xylose-rich media. In addition, XLs reduce the surface tension to $35.9 \mathrm{mNm}^{-1}$ with a CMC of $1 \mathrm{mgL}^{-1}$ and have some antibacterial activity against $S$. aureus [111].

\section{Cellobiose lipids}

Cellobiose lipids (CL), also known as ustilagic acids, consist of cellobiose linked to the terminal hydroxyl group of a fatty acid (Fig. 2e) [112]. Under nitrogen starvation, the fungus $U$. maydis can produce $\mathrm{CL}$ and mannosylerythritol lipids in varying concentrations up to $30 \mathrm{gL}^{-1}$, depending on the carbon source [88]. The studies of this class of biosurfactant are focused on two points. The first, is the structural characterization of the hydrophobic portion, and the second is its antimicrobial potential suggested by the involvement of the cytoplasmic membrane, by the inhibition of some enzymes, and by structural changes in the wall of sensitive microorganisms [113].

Ustilagomycetic yeasts of the genus Pseudozyma are commonly reported as producers of CL. Good examples are P. fusiformata [114], P. aphidis and P. hubeiensis [115]. The CL excreted by $P$. flocculosa, named flocculosine, are well known for their phytopathogenic action against powdery mildew [116], yeasts and Gram-positive bacteria commonly associated with human infections. The CL excreted by Sympodiomycopsis paphiopedili act against Cryptococcus terreus $\left(45 \mu \mathrm{g} \mathrm{mL}^{-1}\right)$ and Candida albicans $\left(160 \mu \mathrm{g} \mathrm{mL}^{-1}\right)$ [117] while those produced by Trichosporon porosum act against Candida albicans $(0.2 \mathrm{mM})$ and Filobasidiella neoformans $(0.03 \mathrm{mM})$ [118].

The CL produced by Cryptococcus humicola are additives for the formulation of colloids applied in the food and cosmetics industries [119]. Sodium salts improves the aqueous solubility of CLs and favours the formation of gels in alcoholic solution (ethanol or 1,3-butanediol) [119, 120]. CL from $C$. humicola, when added to poly (lactic acid) films, modifies the surface properties increasing, for example, its wettability [121].

\section{Polyol lipids}

Polyol lipids (PL) are considered to be an exclusive class of fungal biosurfactants. The main difference of the PL from other glycolipids is the replacement of the hydrophilic portion by a polyol (typically D-mannitol or D-arabitol) linked to an acetylated (R) -3-hydroxy fatty acid [122]. This class of biosurfactants comprises two groups of molecules, the Liamocins (LM), produced by Aureobasidium pullulans (Fig. 2f) [123], and the Polyol Fatty Acid Esters (PEFA), reported in Rhodotorula spp. (Fig. 2g) [124].

Several structures of LM are produced by Aureobasidium melanogenum [125]. The LM are only acylated in the polyol portion, while the PEFA can present different acetylation degrees in the polyol, in addition to an acetylation in the fatty acid portion [122]. Additionally, differences are found in the degree of acetylations in the PEFA depending on the producing fungus, which directly changes the surface properties of the molecule [126].

Regarding the physico-chemical properties, PL densities are higher than water, which favours the recovery of molecules. LM are commonly described as an oily compound, while PEFA have a viscous characteristic [12]. The small portions of the molecule can be modified by polyols supplementation in culture medium [127]. Different LM congeners with different polyol groups have antibacterial activity against strains of Streptococcus spp. [127].

In general, LM have a potential as a new antimicrobial agent group, particularly in prophylactic applications in which a broad spectrum antibiotic may not be the best option [128]. LM inhibits the formation of oral biofilms of S. mutans, S. sobrinus [129] and S. suis mainly by rupturing the pathogen's cell membrane [130].

Limited information are reported on PEFA applicability. The ability to reduce surface tension and its emulsifying capacity are contrasting, but offer promising prospects for therapeutic and environmental applications [18, 131]. The PEFA produced by Rhodotorula paludigena have a high capacity to reduce surface tension $\left(33.84 \mathrm{mNm}^{-1}\right)$ at low CMC (13.18 $\left.\mathrm{mgL}^{-1}\right)$ and they have a superior capacity than Tween 80 to emulsify diesel (77\%) [131]. However, the PEFAs produced by $R$. babjevea reduce surface tension to a lesser extent and have a high capacity to emulsify diesel (70\%) [18].

\section{Lipopeptides}

Lipopeptides (LPP) are composed of a portion of fatty acids with different degrees of branching and oxidation, linked to linear or circular oligopeptides. The peptide varies in number and type of amino acids [26]. Some fungi-produce LPP with active surface properties as described in Table 1. Fusarium sp. BS-8 produces LPP which reduced surface tension 
$\left(32 \mathrm{mNm}^{-1}\right)$ at low CMC $\left(\geq 1.2 \mathrm{gL}^{-1}\right)$ [47]. LPP produced by Mucor circinelloides also reduce the surface tension $\left(26 \mathrm{mNm}^{-1}\right)$ and the viscosity of motor oil by $98.25 \%$, contributing to potential applications in microbial enhanced oil recovery [132]. The cationic lipoprotein produced by Yarrowia lipolytica MTCC 9520 was applied as a stabilizing agent in the synthesis of silver nanoparticles, whose action was to prevent the formation of aggregates and facilitate nanoparticles production [44].

The LPP denoted scopularides produced by Scopulariopsis brevicaulis have activity against several tumour cell lines, i.e., anticancer activity, even at low concentrations $\left(10 \mu \mathrm{g} \mathrm{mL}^{-1}\right)$ [133]. Other LPP called eniatiatins are secreted by Fusarium, Verticillium and Halosarpheia. Eniatiatins are suggested for the treatment and prevention of atherosclerosis and hypercholesterolemia, since they inhibit the enzyme acyl-CoA:cholesterol acyltransferase and alter the concentration of intracellular ions, interrupting cellular metabolism [134].

Among other possible applications, those produced by Candida lipolytica UCP 0988 do not present toxicity against the germination of different vegetable seeds such as Brassica oleracea, Solanum gilo and Lactuca sativa [135], favouring germination in bioremediation soils containing traces of biosurfactants or enhancing water entry for seed germination [136]. In addition, these LPP do not present toxicity to the development of Artemia salina [135], a species of aquatic brine shrimp, enabling the application for remediation of aquatic environments [136].

\section{Hydrophobins}

Hydrophobins are globular proteins, with low molecular weight $(<20 \mathrm{kDa})$ and primary sequence of about $100-150$ amino acids and have 8 cysteine residues that form 4 intramolecular disulfide bonds, stabilizing their tertiary structure and promoting surfactant and emulsifying activity [137, 138]. Hydrophobins are classified into two classes (I and II) according to their assembly characteristics at hydrophobic-hydrophilic interfaces, solubility and hydropathy. Class I hydrophobins form structures similar to amyloid fibrils, termed rodlet layers with a $\beta$-sheet conformation and are soluble only in strong acids, on the other hand, class II hydrophobins form regular crystalline structures with a random spiral conformation and can be easily dissolved with organic solvents or detergents $[139,140]$. Some of these proteins may exhibit glycosylation [137, 139]. Although some hydrophobins can form oligomers as a strategy to increase their solubility in solution, others remain monomeric even at high concentrations [13, 141].

Class I hydrophobins were isolated from Schizophyllum commune (SC3) and class II hydrophobins from Trichoderma reesei (HFBI and HFBII) [138, 139], as well as, several ascomycetes and basidiomycetes capable of secreting hydrophobins in their cell wall, which has an ecological role related to local environment modification [13, 137]. It is believed that these hydrophobins assist hyphae to grow from a liquid phase into air by covering the surface of aerial hyphae with a hydrophobic layer. Likewise, spore dispersal, adhesion, pathogenesis, and breaking surface tension have been linked to hydrophobins [13, 137]. From a biotechnological perspective, due to their high surface activity and nonimmunogenicity, hydrophobins have a versatility of applications as agents for solubilization and delivery of hydrophobic drugs, emulsifying agents for food, protein purification tags, tools for protein and cell immobilization, coatings for biomaterials, biosensors and, biomineralization templates [137, $140,142]$. Although there is a growing potential to manipulate hydrophobin variants for specific applications by protein engineering and heterologous expression in host cells, the insertion of these molecules into commercial applications is still limited due to low productivity, the need for additional steps for recovery and post-transcriptional modifications of the surfactant protein $[137,140]$.

\section{Fungi-producing biosurfactants: bioprospecting and isolation sources}

Fungi have ubiquitous habitat which can influence the production of different metabolites. The microbial ecology involved in the production of biosurfactants can indicate possible sites of isolation and/or application of the molecules obtained from these organisms. Several theories were proposed to explain the evolution behind microbial biosurfactant production. The first involves emulsification and solubilization of hydrophobic substrates to create a microenvironment favourable to the growth and production of the organisms [143]. The second, involves the adhesion-release of the cell to surfaces: when associated with the walls, they can regulate the properties of the cell surface, increasing the permeability of the membrane, for example. In this way, they use the property of active surface to detach themselves from unfavourable environments or in the search for new habitats with greater availability of nutrients [144]. The third, presenting antibiotic activity as a defence mechanism against possible competitors for substrates [145]. Fourth, as an energy reserve, since they can enter the catabolic process as a possible source of energy during periods of nutrient limitation [146, 147] and finally as protection for the microorganism against environments with high osmotic pressure, ionic imbalances and as protection against freeze/ thaw cycles [148].

The isolation of fungi dependents on accessing environments where biosurfactant-producing strains are thriving. Although cultivable microorganisms represent less than $1 \%$ 
of the diversity of known microbial species [149], the bioprospecting of fungal strains by culture-dependent technique has enabled the discovery of new biosurfactant-producing strains [147] as well as novel biosurfactant structures [150]. Biosurfactant-producing fungi were isolated from hydrocarbon/petroleum contaminated soil samples [151], plant structures such as roots [40], stems [147], leaves [147], cones [152], flowers [150], fruits [153]; and animals such as porifers [43] and arthropods [154].

On the other hand, the search for biosurfactant-producing fungi can also be carried out through approaches that exploit extreme environments [155] and cultivation-independent techniques (metagenomics), as total environmental DNA can be examined at sequence level or be function-oriented [149, 156]. Functional metagenomics identifies genes or pathways in an environmental clone library by their functional activity (in this case, produce biosurfactants), providing an advantage over sequence-based screening, principally due to the fact that no prior knowledge of the gene sequence for target activity is required [157]. Likewise, metagenomics coupled with next-generation sequencing has enabled wider access to the diversity and function of many microorganisms in nature [158]. In addition, genetic information from nonculturable microorganisms can be exploited for enhanced biosurfactant development [149]. However, there are few published studies that employed metagenomics to prospect for biosurfactant-producing microorganisms [159]. The main limitation for metagenomic biosurfactant discovery may be due to the complex regulatory mechanisms involved in its production [156].

\section{Biosurfactants in cold environments}

Although extremophilic microorganisms are potential producers of biosurfactants, as they can excrete them for their colonization in adverse environment, biotechnological production from these microorganisms is virtually unexplored [160]. The bioprospecting of cold-adapted microorganisms has promoted the discovery of previously undescribed bacteria for biosurfactants production [161], however, studies focused on fungal strains remain scarce.

Filamentous fungi isolated from Antarctic soils such as Thelebolus sp. [33] and Phoma herbarum CCFEE 5080 produced EPS at 1.94 and $13.6 \mathrm{gL}^{-1}$, respectively, that may act as necessary protection to microclimatic conditions, characterized by low temperatures, high thermal fluctuations and repeated freeze-thaw cycles [148]. Mortierella sp., isolated from arctic soils contaminated by hydrocarbons are suspected to produce biosurfactants [162], since new biomolecules (Malpininas and Malpibaldinas) with emulsifying properties were produced by zygomycetes such as Mortierella alpina ATCC32222 and DH187 [163]. In addition, extremophilic yeast Moesziomyces antarcticus (previously classified as Candida antarctica) produced biosurfactants such as mannosylerythritol lipids [164] and diacylmannosylerythritol [165], the latter interfered with ice paste formation as they have an anti-agglomeration effect and a high ice packing factor [161]. Among 68 yeasts isolated from Antarctic soils, only 11 produced biosurfactants, with Candida glaebosa as the most prominent [155]. Recently, other yeasts isolated from Antarctic marine and terrestrial environments such as Meyerozyma guilliermondii L21, Cryptococcus victoriae $\mathrm{L} 92$ and Leucosporidium scotti $\mathrm{L} 120$ have been reported as biosurfactant producers [166].

Research on biosurfactants produced by microorganisms in cold environments establishes a turning point for bioprocess work carried out at low temperatures, without the need for heating, and action on surfaces with low temperatures [164, 167]. Cold-adapted microorganisms are able to produce biosurfactants at low Krafft temperature (Fig. 1g), i.e., it allows their solubilization, micelle formation and application even at low temperatures [36]. Thus, these biosurfactants could be used as ingredients in antifreeze additives, cold detergents and to improve flow properties at freezing temperatures in biodiesel production [164]. However, the difficulty to mimic extreme conditions in vitro that allows the synthesis of the bioproduct is still a challenge to be overcome [160].

\section{Screening of biosurfactant-producing fungi: methodologies and characterization}

The presence of biosurfactants in culture media can be assessed by a various qualitative and/or quantitative methods that have different accuracy [168]. Generally, the screening tests depend on the analysis of microbial metabolites produced by fungal strain during or after cultivation [38]. These tests are based on direct measurement of surface tension, indirect methods of surface activity, emulsification index and/or cellular hydrophobicity [25]. The use of single techniques for screening can exclude strains that other techniques may have been able to detect [168]. The desired strains are those that produce biosurfactants with the lowest $\mathrm{CMC}$ values and with highest surface tension reduction or emulsification activity. In this regard, the screening tests must be developed and established considering the addition of inducing substrates under different processing conditions [38]. Methodologies are constantly being improved to screen high numbers of isolates and correlate the findings with available data $[169,170]$, as well as, for screening clones from metagenomic libraries [159]. Molecular techniques could be applied to screen strains with single gene clusters and islands of inherent production capacity, which would also facilitate the process and identification of similar gene sequences in other strains [171]. 
After selecting the producing strain, the fungal strain must be essentially identified from their genetic sequencing through the region of the Internal Transcribed Spacer (ITS) $[151,168]$. The results should be compared with similar strains of the type of different species within the genus through multiple sequence alignment, ensuring unambiguous identification of the inoculum [168].

\section{Surface tension measurement}

In the last 20 years, measuring the surface/interfacial tension of culture supernatants and/or filtrates has been the main semi-quantitative parameter used to confirm the presence of biosurfactants $[172,173]$. This methodology is sensitive, since the reduction in surface/interfacial tension is quantified until reaching the $\mathrm{CMC}$, due to the saturation of this reduction, i.e., the numerical value obtained in the analysis only indicates if the microbial culture is producing biosurfactants or not. Therefore, it cannot be considered a quantitative parameter [9]. The positive criteria for biosurfactants production is the reduction of the surface tension to less than or equal to $35 \mathrm{mNm}^{-1}$ [30].

The surface or interfacial tension can be measured by several methods (du Nouy Ring, Wilhelmy Plate, Spinning Drop, Pendent Drop), with the du Nouy Ring method being the most used. This determination is made by a tensiometer and/or goniometer $[174,175]$. The main advantage of this method is accuracy and the absence of false-negative results $[176,177]$. This technique requires specialized equipment and the analysis can be time-consuming, since simultaneous measurements are not possible and it requires an interval between each sample preparation (washing, wire buckling/ platinum plate) $[25,178]$.

\section{Drop collapse test}

The drop collapse test is based on the collapse of a drop when in contact with a hydrophobic surface. There is a directly proportional correlation between the drop diameter and the surfactant concentration, also indicating a semiquantitative parameter for the presence of biosurfactants $[176,179]$. This assay can be carried out in 96-well microplates, which indicates high-throughput screening (Fig. 3a) [180, 181]. An adaptation of this method is the use of a hydrophobic surface of the commercial product parafilm$\mathrm{M}^{\mathrm{TM}}$ (Parafilm-M Test) to facilitate visualization (Fig. 3b) [182]. Some authors have used methylene blue to stain samples to improve the visualization, as it does not influence in the drops shape [182, 183].

The drop collapse/parafilm-M test is accurate in distinguishing between producing and non-producing strains, with few false-negatives. This test is a quick and simple test that does not require specialized equipment and can be performed with a small volume of sample [152, 178].

\section{Oil spreading}

The oil spreading test is based on the principle of decreasing the interfacial/superficial tension between the water and oil phases [178, 184]. If a biosurfactant is present, there will be a destabilization in the intermolecular forces of the water/ oil interface with the active surface molecule, displacing

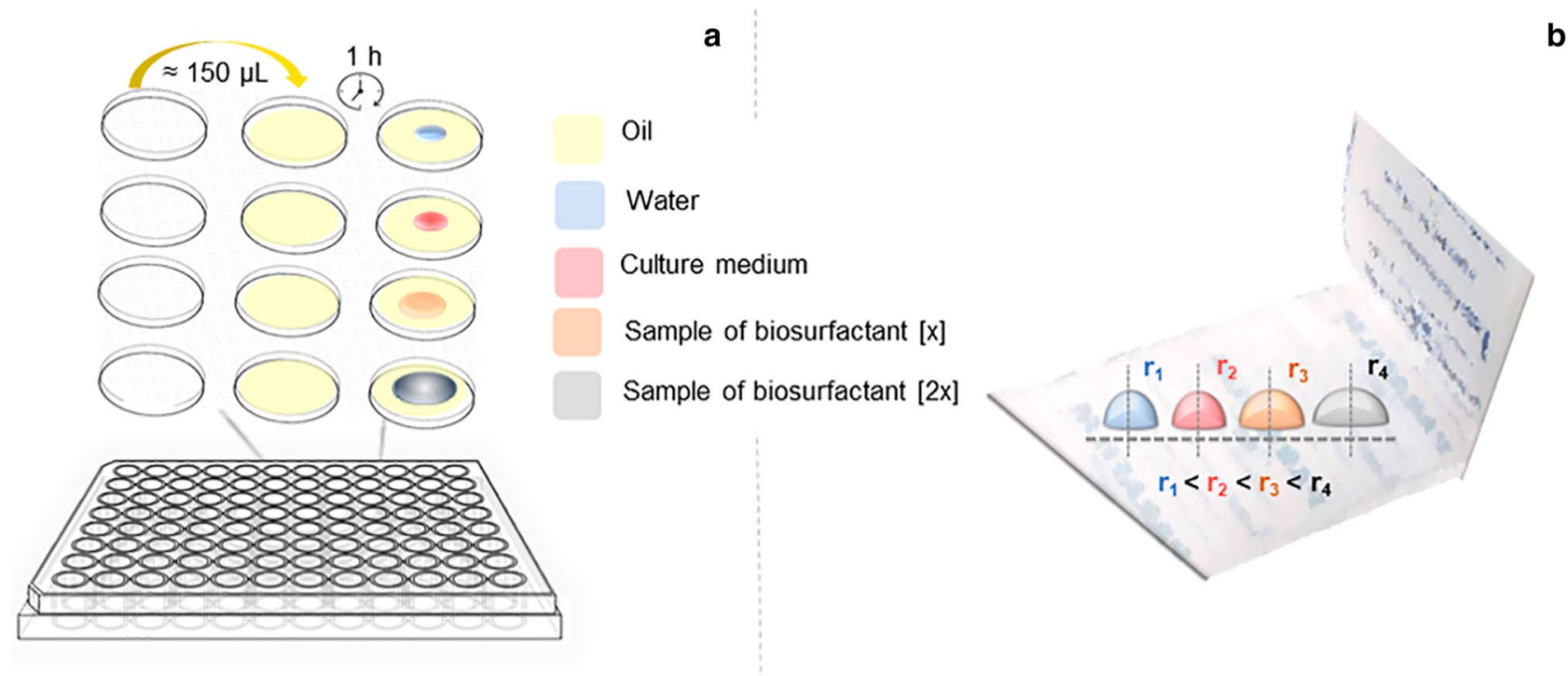

Fig. 3 Collapse drop test occurs with the addition of oil and samples $(3: 1 \mathrm{v} / \mathrm{v})$ to the wells of the microplate. First, oil is added to form a hydrophobic surface. Afterwards, drops of samples containing bio- surfactants will collapse on contact with this surface as shown in a, and Parafilm-M test in $\mathbf{b}$, where $r_{\mathrm{n}=1,2,3,4}=$ drop radius and $n$ analyzed sample 
the volume of the oil on the surface (Fig. 4) [178]. As the repulsion between the oil and water molecules is reduced, the oil is displaced in proportion to the biosurfactant concentration. Thus, a semi-quantitative parameter is provided for the selection of strains with the greatest production potential [185]. This methodology is considered sensitive, reliable, fast, and easy to perform. However, large volumes of waste are generated [43, 153, 186].

\section{Emulsification index}

The emulsification activity was initially proposed through spectrophotometric analysis that require sophisticated equipment $[48,180]$. However, the Emulsification Index $\left(\mathrm{EI}_{24}\right)$ is a simpler, effective and commonly used method that consists of measuring the ratio between the emulsified volume and the total volume of the analysed sample (Fig. 5) [187]. Both methodologies are widely used $[188,189]$. The $\mathrm{EI}_{24}$ is easy to perform and is considered as an appropriate indicator for strain screening, but a large volume of waste is produced [31].
The $\mathrm{EI}_{24}$ shows the molecule capacity in forming stable emulsions between different immiscible phases i.e., this index acts independently of the effect of surface tension of the medium to prevent drop coalescence [190]. Biosurfactants contained in the samples, upon contact with hydrophobic substrates, will reach an equilibrium phase between oil/water/biosurfactant system and promote solubilization to form emulsions $[185,191]$. This functional property has been used to assess the biosurfactant ability to form and stabilize emulsions on different hydrophobic substrates, organic solvents and environmental conditions [35, 38, 192]. The emulsions stability is influenced by the compaction and size of the globules. Emulsions with low compaction and large globules generally show reduced stability [193]. An important characteristic in the emulsion stabilization is the adsorption of the emulsifier at the liquid-liquid interface [194].

The ability of a molecule to form stable emulsions is not always associated with the ability to reduce surface tension. It is suggested that strains producing biosurfactants are also producers of bioemulsifiers, but not the other way around $[178,195]$. Therefore, the emulsification index provides
Fig. 4 The oil spread test occurs with the addition of water and a smaller volume of oil to form a thin hydrophobic layer. Then, the test sample is added over the oil layer and provides the displacement of the area on the oil surface
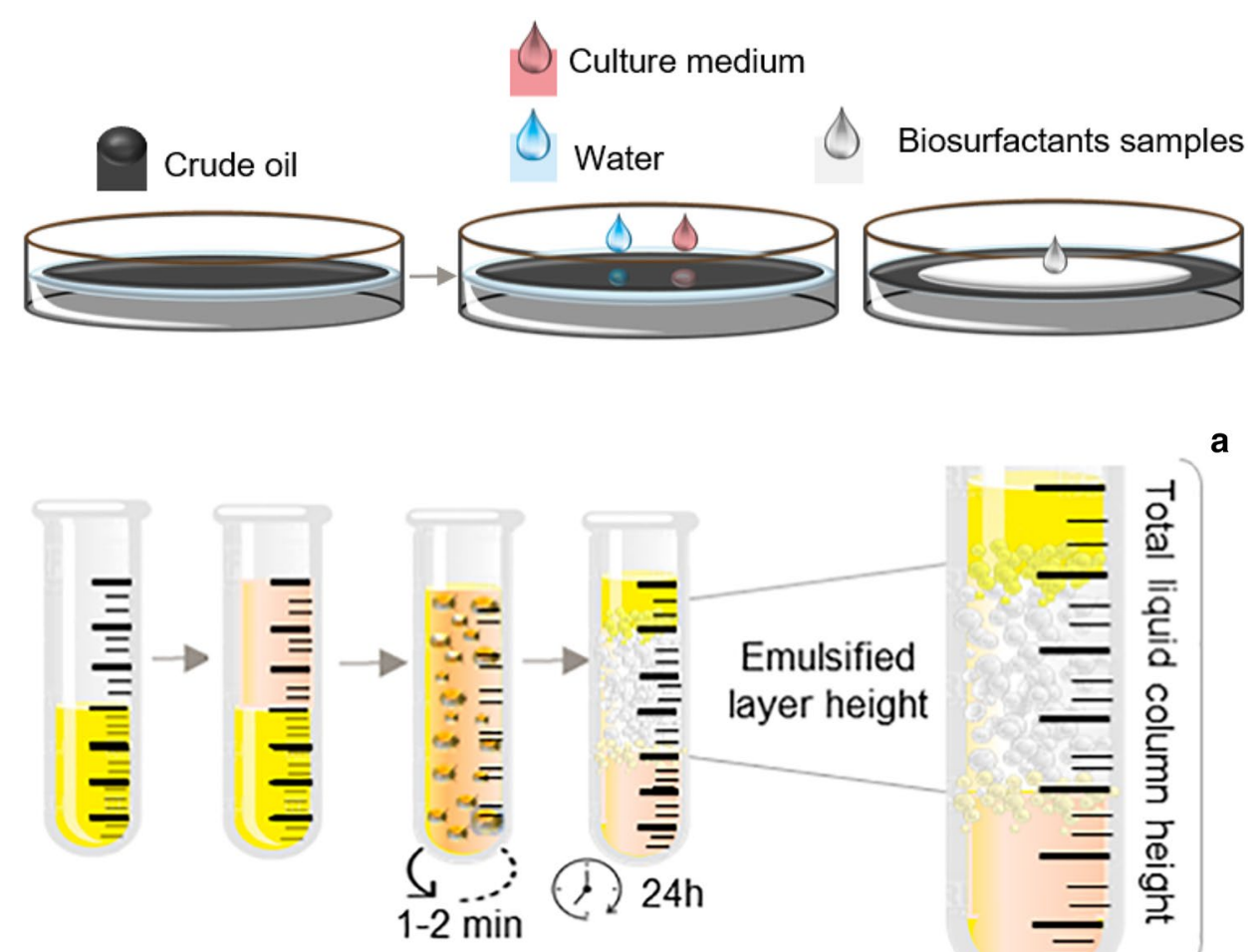

a

Fig. $5 \mathrm{EI}_{24}$ test: addition of equal volumes (1:1) of hydrophobic substrates and samples containing biosurfactants in graduated tubes. Subsequently, the mixture is stirred at high speed, being maintained in the absence of disturbance for phase separation and stability of the formed emulsion (a). The emulsification percentage value can be measured according to (b) 
a perspective on the production of bioemulsifiers by the selected isolates.

\section{Cell adhesion to hydrocarbon hydrophobicity analysis}

The Microbial Adhesion To Hydrocarbon (MATH) test is based on the cell surface hydrophobicity [196]. There is a direct correlation between the cell surface hydrophobicity and its adhesion in hydrocarbon droplets, which favours emulsification and assimilation of hydrophobic substrates (Fig. 6) [197, 198]. This test measures the partition of cells between the aqueous and hydrophobic phases. The fungus surface is considered hydrophobic when more than $50 \%$ of the cells migrate from the buffer (PUM - phosphate, urea, magnesium) to the hexadecane. On the other hand, it is considered hydrophilic when more than $50 \%$ of the cells remain in the buffer [199].

Few reports were found in the literature for superficial hydrophobicity of filamentous fungi [200]. Therefore, it is necessary to search for new effective methodologies to improve on existing measurements of cellular hydrophobicity of filamentous fungi which is affected by differentiated mycelial growth, cultivation conditions and the physiological state of strains [138]. Sampling for the MATH may cause hyphae fragmentation, phase separation, possibly changes in hydrophobicity affecting standardization and resulting in incorrect measurements [201, 202].

\section{Methylene CTAB-Blue agar plate method and blood haemolysis}

Methylene Blue Agar-CTAB method is selective for extracellular anionic biosurfactants, since halos formed in the culture are the result of insoluble salts produced between the anionic biosurfactant and the cationic detergent Cetyltrimethylammonium Bromide (CTAB) [203]. This test is qualitative, considered a primary screening study, easy to perform and to view responses (Fig. 7a) [40, 152, 204, 205].

The CTAB assay is widely reported in the literature with consistent results for screening bacteria and yeasts. However, the CTAB method presents limitations for filamentous fungi, as it may underestimate positive results due to the spread of mycelial growth, production of metabolites involved in the dye degradation and dye absorption [205, 206].

The blood haemolysis test was developed for the selection of bacteria producing biosurfactants [207]. However, it has recently been used to prospect for filamentous fungi and yeasts producing biosurfactants (Fig. 7b) [40, 208, 209]. The haemolysis results from the lysis of erythrocytes due to disintegration of cell membranes due to activities of some surfactant [209, 210].

The limitations of the blood haemolysis test are related to difficulties in maintaining the culture conditions in the blood agar media that would favour the production of biosurfactants in addition to possible interference of microbial haemolysins with the results [154]. Low biosurfactant concentration produced can also present weak diffusion in the solid medium and favour the non-formation of halos [25]. Some results of blood haemolysis tests for fungi and yeasts

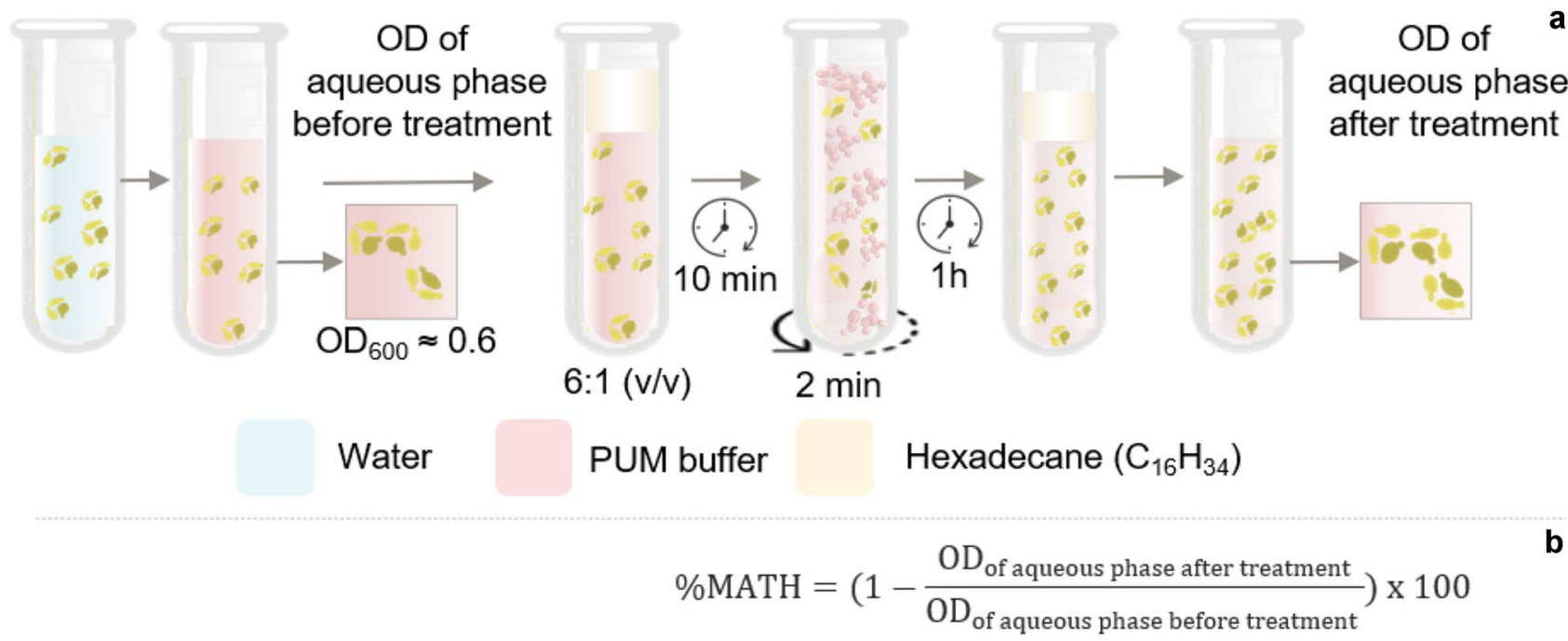

Fig. 6 The microbial adhesion to hydrocarbon test is initiated by washing fungal cells to remove contaminants, followed by a resuspension in buffer solution (PUM) until reaching a standardized optical density (DO). Thereafter, the hydrocarbon is added, and the mixture is stirred. After complete separation of phases, the organic phase is removed, and the optical density is measured again (a). The percentage value of microbial cell adhesion to hydrocarbons is obtained as in (b) 


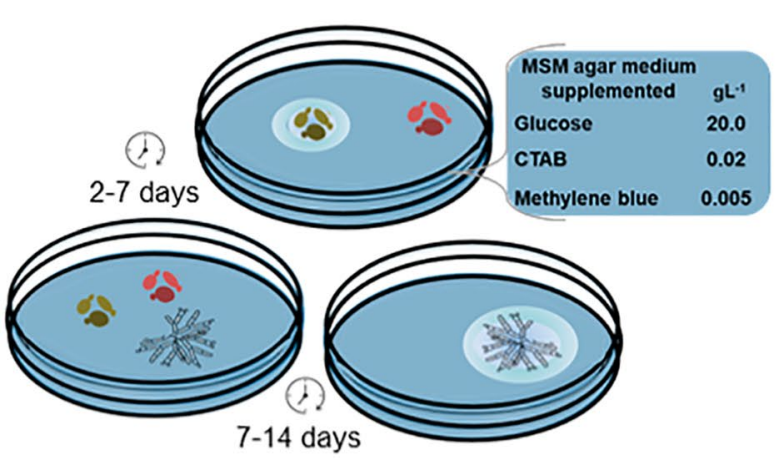

a

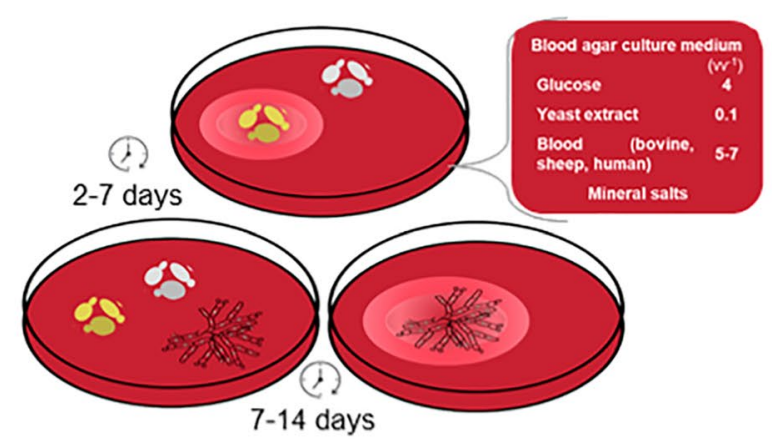

b

Fig. 7 Methylene blue-CTAB agar test (a) and blood hemolysis test (b). Biosurfactant-producing strains produce a halo when grown in a solid medium of defined composition. The cultivation period for obtaining the results varies according to culture strain

have been shown to be false-negatives, as they have shown negative results for haemolysis while other positive results are obtained for different tests of surface activity and/or emulsification indexes $[40,67,154]$. Therefore, due to the variability of the results, other screening tests must be associated with blood haemolysis to corroborate biosurfactant production.

\section{High-throughput screening, microplate and penetration assays}

The application of two or more methods for preliminary confirmation of biosurfactant producer strains takes longer time, as does the interval between inoculation and production of biosurfactants. High-throughput screening involves the development and execution of rapid methods applied to a large number of isolates. Currently, there are only few screening procedures for biosurfactant detection considered as "high yielding". Microplate and penetration assays are carried out in 96-well microplates, which increases the number of tested strains and require lower sample volumes [25, 180, 211].

The samples analysed by microplate test are visually inspected. The test provides a qualitative result for biosurfactants presence due to the optical distortion promoted instantly in the image. If there are biosurfactants in its composition, the image formed on the microplate is modified (Fig. 8a) [204, 212]. On the other hand, the penetration test a

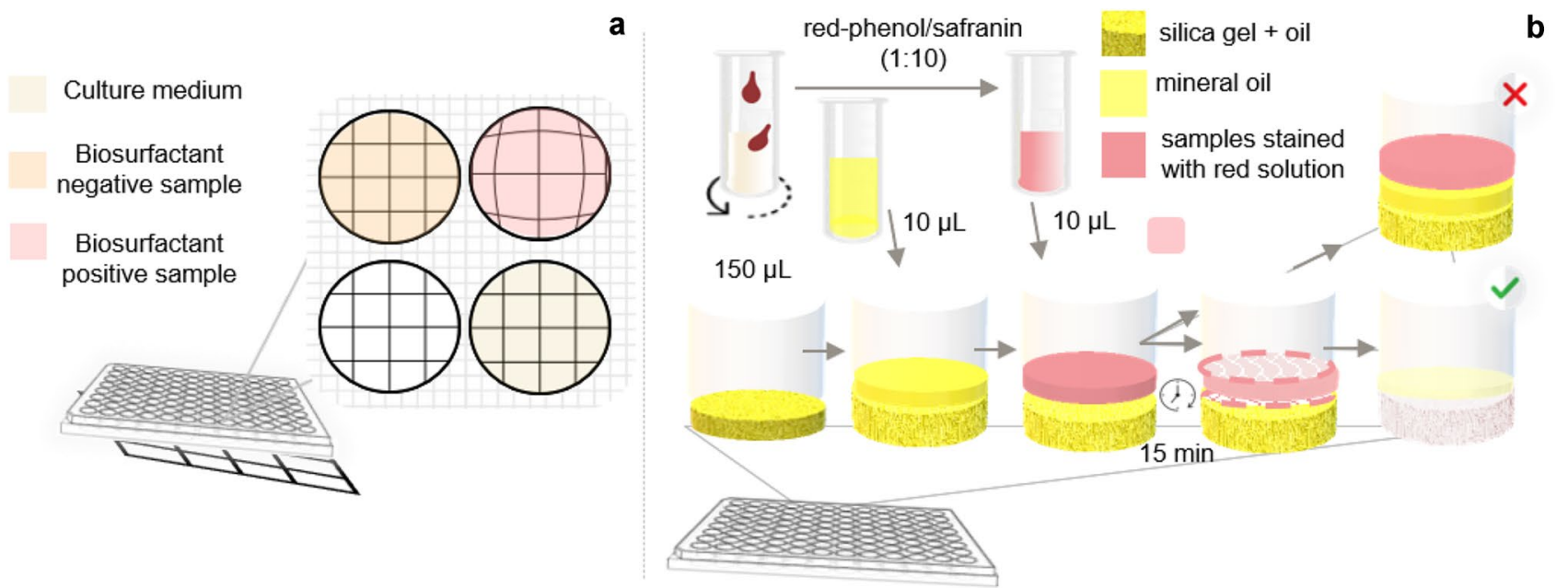

Fig. 8 Microplate assay is initiated by placing a grid paper under a microplate. The culture medium/water in a microplate well is considered to have a flat surface. A sample with biosurfactant will have a change at the well edge and the fluid surface will become concave, and consequently distorts the image (a). The penetration test occurs by adding a hydrophobic paste to the wells of the microplate, which is covered with mineral oil. Then, the sample is stained with red solution and added to the hydrophobic surface. The presence of biosurfactants is detected through its influence on the rupture of the barrier (interface) of the oil layer in the paste, which favors the entry of silica into the hydrophilic phase, and the upper phase changes the color from light red to cloudy white (b) 
is colorimetric and involves two insoluble phases. The direct contact between these phases changes the analysed sample's colour in the presence of biosurfactants, because it allows for the interaction between phases (Fig. 8b) [25].

\section{New production technologies}

Biosurfactants are considered extracellular or cell membrane-associated secondary metabolites and have an ecological role similar to antibiotics and pigments that interact in membrane regulation $[59,154,213]$. However, some authors report that biosurfactant biosynthesis is associated with microbial growth when hydrophobic substrates are used, which indicates that these primary metabolites may also facilitate the absorption of substrates for fungi development $[151,198,214]$. Fungi have a more rigid and complex cell wall composition, i.e., they are more resistant to high concentrations of biosurfactants during cultivation, while bacteria have more sensitive cell structures [209, 215].

In most cases, fungal biosurfactants are produced by submerged cultures conducted in shaking flasks and/or bioreactors [216, 217]. Solid-state production is also promising [55] A recent study showed 39\% of published research articles on biosurfactant production through solid cultivation are fungal, among which SL represent 14\% and hydrophobins $2 \%$ of the types produced [55]. Solid-state cultivation promoted the production of hydrophobins by Purpureocillium lilacinum $\left(34.8 \mathrm{mNm}^{-1}\right.$ and $1.3 \mathrm{mg}$ of protein $\left.\mathrm{g}^{-1}\right)$, which did not occur in submerged culture [141]. Moreover, a 107\% increase in yield was achieved in solid culture with complex substrate (sesame oil cake) compared to submerged culture using YMG medium for production of hydrophobins from Pleurotus ostreatus. [218].

Most studies on cultivation in solid medium for biosurfactant production are conducted in complex residues (agroindustrial) [218], which can make extraction difficult due to the greater diversity of interaction (product-medium and medium-solvent), maintaining residual impurities in the recovered extract [55]. In addition, solid-state cultivation scale presents challenges to be overcome on an industrial scale, such as the design of bioreactors that allow automated control and monitoring of parameters of the cultivation process $[219,220]$, as well as minimizing heterogeneity in terms of heat and mass transfers [55]. However, solid-state cultivations avoid possible problems associated with foaming or high viscosity commonly reported in submerged cultures [221].

\section{Nutritional parameters and multiple metabolites}

In general, culture medium is mainly composed of a carbon and nitrogen source plus macro and micronutrients [23], as well as, its price corresponds to about $10-30 \%$ out of total cost of the product [222]. Thus, culture medium composition may be considered the main cost reduction strategy in a bioprocess [23]. Likewise, the cultivation systems with multiple metabolite production have been reported as an effective approach to improve process profitability due to the use of more efficient types of bioreactors and substrates $[19,132]$.

Simultaneous production of biosurfactants and other bioproducts, using an integrated platform concept, can also be an economic strategy [18]. Garay et al. [223] reported the production of PEFA and intracellular triacylglycerols (TG) by Rhodotorula paludigena (20.9 $\mathrm{gL}^{-1}$ PEFA and $\left.8.8 \mathrm{gL}^{-1} \mathrm{TG}\right)$ and Rhodotorula babjevae $\left(11.2 \mathrm{gL}^{-1}\right.$ PEFA and $\left.18.5 \mathrm{gL}^{-1} \mathrm{TG}\right)$. In optimized culture conditions, $R$. paludigena produced the highest yield of PEFA $\left(48.5 \mathrm{gL}^{-1}\right)$ and intracellular lipids $\left(16.9 \mathrm{gL}^{-1}\right)$ ever reported. The lipid sources produced are substrates for the biofuel production industry [131].

In other cases, biosurfactant production is also associated with the excretion of hydrolytic enzymes such as lipases, proteases and amylases [224, 225]. The fungus Pleurotus sajor-caju simultaneously produces biosurfactants $\left(4.01 \mathrm{gL}^{-1}\right)$ and ligninolytic enzymes (laccase, manganese peroxidase and lignin peroxidase) in solid-state cultivation with sunflower seed husks as substrate [226]. In addition, $P$. antarctica PYCC 5048 produces MEL and xylanolitic enzymes from the direct conversion of xylan in a single step, without the need for enzymatic supplementation [227].

An unidentified yeast isolated from fresh rhizosphere samples of healthy planted crops have lipolytic activity and produce biosurfactants when grown on hydrophobic substrates [40]. Lipases and biosurfactants may act in synergism to favour the bioavailability of these substrates from the hydrolysis of complex biopolymers for cell growth [164]. If additional steps are necessary for the recovery of the produced co-products, harvesting two products (lipases and biosurfactants) in a single bioprocess can be a promising strategy to improve overall process profitability.

\section{Carbon sources}

The carbon sources initially provided and utilized in the culture medium interfere in different metabolic pathways for biosurfactant production [228]. The combination of energy sources, such as carbohydrates and lipids in culture medium, has been commonly reported $[229,230]$. In this context, several sources of carbon can be used in culture media such as glucose, sucrose [231], xylose [227], inulin [131], cassava wastewater [28], cane molasses [232], soy molasses [233], glycerol [234] and hydrolyzates from restaurant food waste [235]. Additionally, lipid sources, such as refined vegetable oils and residual food frying oils [71, 208, 230, 236], wastewater from the oil industry [186, 237], motor oil [151] and 
animal fat $[44,238]$, have also been used. In addition, the carbon source supply directly influenced the chemical composition and surfactant properties of sophorolipids produced when S. bombicola was grown in biodiesel or rapeseed oil, with biodiesel a new esterified sophorolipid structure was produced with lower CMC value and surface tension [239].

In general, non-residual and non-traditional substrates showed low productivity values for sophorolipid production by $S$. bombicola even when supplemented with glucose. As examples, petroselinic acid (positional isomer of oleic acid) $\left(0.24 \mathrm{gL}^{-1} \mathrm{~h}^{-1}\right)$ [240]; horse oil (composed of linoleic, palmitoleic fatty acids and unsaturated) $\left(0.40 \mathrm{gL}^{-1} \mathrm{~h}^{-1}\right)$ [241]; castor oil (Ricinus) $\left(0.20 \mathrm{gL}^{-1} \mathrm{~h}^{-1}\right)$ [242]; jatropha oil (Jatropha curcas) $\left(0.03 \mathrm{gL}^{-1} \mathrm{~h}^{-1}\right)$, karanja oil (Pongamia) $\left(0.03 \mathrm{gL}^{-1} \mathrm{~h}^{-1}\right)$ and neem oil (Azadirachta) $\left(0.01 \mathrm{gL}^{-1} \mathrm{~h}^{-1}\right)$ [243]. This is probably due to the composition of fatty acids and also the presence of inhibitory compounds in these substrates [243].

Lignocellulosic hydrolyzates have been used to produce MEL and sophorolipids, although the presence of sugar dehydration, such as furfural and hydroxyl-methyl furfural had an inhibitory effect on the production [209, 244]. The hydrolyzates detoxification processes can partially remove those inhibitors [209, 230], since the yield of sophorolipids was doubled when hydrolysate from detoxified corn straw and oleic acid were used as carbon sources for S. bombicola [230].

A variety of agro-industrial by-products are reported for the production of biosurfactants through solid-state cultivation, such as oil cakes from the oil refining industry with the addition of beet molasses [220], soybean bran, husk, rice straw and bran [216, 245], wheat bran, soybean seeds, peanuts [246], grape residues and potato skins [247]. In this context, substrates for solid-state cultivation, as digestate from biowaste supplemented with glucose and fats $\left(0.02 \mathrm{~g} \mathrm{~g}^{-1}\right)$ and stearic acid $\left(0.211 \mathrm{~g} \mathrm{~g}^{-1}\right)$ showed low yield for sophorolipids production [248, 249].

\section{Nitrogen sources}

Different sources of inorganic and organic nitrogen can influence biosurfactants synthesis. The corn-steep liquor (CAS 66071-94-1), yeast extract and urea are organic sources, as well as nitrate and ammonium salts are inorganic sources commonly used [250, 251] Normally, during cell growth excess carbon and nitrogen sources is suggested, followed by depletion of the nitrogen source $[29,252]$. The $\mathrm{C} / \mathrm{N}$ ratio can interfere with biosurfactant production, so it is recommended to maintain a high $\mathrm{C} / \mathrm{N}$ ratio during cultivation, observing a range of 16:1-18:1 [34, 193].

The physico-chemical properties of biosurfactant can be modified by providing different nitrogen sources. Inorganic nitrogen sources were more suitable than organic sources for the production of sophorolipids, this latter promoted preferably lactonic and low polarity sophorolipids [253], as well as the substitution of peptone for tryptone in the culture medium reduced the emulsification index of the biosurfactants produced by Aspergillus flavus [41].

\section{Trace elements}

Although natural by-products contain several nutrients due to their complex composition, the amounts of nutrients are suboptimal [254]. Supplementation with amino acids [163] and micronutrients such as magnesium, phosphorus, sodium, copper and manganese can meet these nutritional requirements and favour biosurfactant production [81, 84]. Optimizing the concentration of nutrients (phosphate salts, sulphates and chlorides) in the culture medium using response surface methodology increased MEL production at $61 \%$ by Ceriporia lacerate [84]. Culture media containing peptone, copper and manganese salts provided greater production of MEL-A homologues by $P$. aphidis ZJUDM34 compared to media without these microelements [81]. Metallic ions can influence the selective production of different sophorolipids by Wickerhamiella domercqiae, since lactonic congeners were mainly produced in the presence of $\mathrm{Mg}^{2+}$ ions, while $\mathrm{Fe}^{2+}$ ions promoted the production of acidic sophorolipids, as well as $\mathrm{Cu}^{+2}$ ions favoured maximum productivity $\left(0.89 \mathrm{gL}^{-1} \mathrm{~h}^{-1}\right)$ [255]. The synthesis of sophorolipids by S. bombicola was increased by approximately $17 \%$ due to the addition of $\mathrm{Mg}^{2+}, \mathrm{Mn}^{2+}, \mathrm{Cu}^{2+}$ and principally $\mathrm{Fe}^{+2}$ to a specific concentration, decreasing slowly with additional increase of ion concentration [230].

\section{Strategies for increasing yield and productivity}

During biosurfactant production, cell aging, depletion of nutrients or the accumulation of product and/or by-products can inhibit cell activity and reduce biosurfactant production rate [256]. Process yield, chemical structures and physicochemical properties vary according to substrates composition, producing-strains and cultivation system (batch, fedbatch, semi-continuous) [186, 257]. In addition, changes in cultivation parameters and conditions such as volume of inoculum and absence of agitation resulted in product with different emulsifying properties, surface activity and yield by Mucor hiemalis [208]. Table 2 shows a survey of the main components of the culture medium, parameters process and the kinetic values related to fungal biosurfactant production in agitated flasks, bench-top and pilot scale bioreactors.

As a rule of thumb, $50 \mathrm{gL}^{-1}$ is the minimum acceptable titre for any basic chemical produced and can be higher in many cases. Productivity below $2.0 \mathrm{gL}^{-1} \mathrm{~h}^{-1}$ is generally unmarketable due to the high capital costs [258]. According to Table 2, only strains of $S$. bombicola show productivity 
Table 2 Survey of fungal biosurfactants production parameters found in the literature

\begin{tabular}{|c|c|c|c|c|c|c|c|c|c|}
\hline $\begin{array}{l}\text { Producer } \\
\text { microorgan- } \\
\text { ism }\end{array}$ & $\begin{array}{l}\text { Substrates } \\
(\mathrm{C} / \mathrm{N})\end{array}$ & $\begin{array}{l}\text { Working } \\
\text { volume } \\
\text { (L) }\end{array}$ & Mixing (rpm) & $\begin{array}{l}\text { Aeration } \\
(\mathrm{vvm})\end{array}$ & $\begin{array}{l}\mathrm{pH} / \text { tempera- } \\
\text { ture }\left({ }^{\circ} \mathrm{C}\right)\end{array}$ & $\begin{array}{l}\text { Volumetric } \\
\text { productivity } \\
\left(\mathrm{gL}^{-1} \mathrm{~h}^{-1}\right)\end{array}$ & $\begin{array}{l}\text { Maximum } \\
\text { yield } \\
\left(\mathrm{gL}^{-1}\right)\end{array}$ & $\begin{array}{l}\text { Surface } \\
\text { tension } \\
\left(\mathrm{mNm}^{-1}\right)\end{array}$ & References \\
\hline $\begin{array}{l}\text { Candida } \\
\text { lipolytica }\end{array}$ & $\begin{array}{l}\text { Animal fat } \\
(5 \%) \text { and } \\
\text { corn-steep } \\
\text { liquor } \\
(2.5 \%)\end{array}$ & 50.0 & 200 & ND & $5.3 / 28$ & 0.30 & 40.00 & 25.00 & [136] \\
\hline $\begin{array}{l}\text { Candida } \\
\text { tropicalis } \\
\text { UCP0996 }\end{array}$ & $\begin{array}{l}\text { Frying oil } \\
(2.5 \%), \\
\text { corn liquor } \\
(2.5 \%) \text { and } \\
\text { cane molas- } \\
\text { ses }(2.5 \%)\end{array}$ & 25.0 & 200 & 1.0 & $5.5 / 28$ & 0.06 & 7.36 & 27.48 & [232] \\
\hline $\begin{array}{l}\text { Candida } \\
\text { sphaerica }\end{array}$ & $\begin{array}{l}\text { Ground-nut } \\
\text { oil refinery } \\
\text { residue } \\
(9 \%) \text { and } \\
\text { corn-steep } \\
\text { liquor (9\%) }\end{array}$ & 20.0 & 150 & ND & $5.3 / 27$ & 0.15 & 21.00 & 27.00 & [22] \\
\hline $\begin{array}{l}\text { Candida } \\
\text { antarctica }\end{array}$ & $\begin{array}{l}\text { Soybean oil } \\
\left(80 \mathrm{gL}^{-1}\right) \\
\text { and yeast } \\
\text { extract } \\
\left(1 \mathrm{gL}^{-1}\right)\end{array}$ & 2.0 & 200 & 1.0 & ND & 0.19 & 28.00 & 35.00 & [217] \\
\hline $\begin{array}{l}\text { Starmerella } \\
\text { bombicola }\end{array}$ & $\begin{array}{l}\text { Glucose } \\
(10 \%) \text {, sun- } \\
\text { flower acid } \\
\text { oil }(10 \%) \text {, } \\
\text { yeast } \\
\text { extract } \\
\left(4 \mathrm{gL}^{-1}\right) \\
\text { and urea } \\
\left(1 \mathrm{gL}^{-1}\right)\end{array}$ & 2.0 & 550 & 1.0 & $3.5 / 30$ & 0.27 & 51.50 & 35.50 & [59] \\
\hline $\begin{array}{l}\text { Starmerella } \\
\text { bombicola }\end{array}$ & $\begin{array}{l}\text { Glucose } \\
\left(100 \mathrm{gL}^{-1}\right) \\
\text { and corn- } \\
\text { steep liquor } \\
\left(10 \mathrm{gL}^{-1}\right)\end{array}$ & 2.5 & 800 & 1.0 & $3.9 / 25$ & 1.55 & 342.00 & ND & {$[250]$} \\
\hline $\begin{array}{l}\text { Pseudozyma } \\
\text { tsukubae- } \\
\text { nsis }\end{array}$ & $\begin{array}{l}\text { Cassava } \\
\text { wastewater }\end{array}$ & 3.0 & $100 / 150$ & 0.4 and 0.8 & ND & 0.02 & 1.26 & 26.00 & [28] \\
\hline $\begin{array}{r}\text { Rhodotorula } \\
\text { paludigena }\end{array}$ & $\begin{array}{l}\text { Glucose } \\
\left(150 \mathrm{gL}^{-1}\right) \\
\text { and yeast } \\
\text { extract } \\
\left(1.5 \mathrm{gL}^{-1}\right)\end{array}$ & 4.0 & ND & 1.0 & $6.5 / 27$ & 0.12 & 20.90 & ND & [223] \\
\hline $\begin{array}{l}\text { Aureoba- } \\
\text { sidium } \\
\text { pullulans }\end{array}$ & $\begin{array}{l}\text { Sucrose } \\
\left(50 \mathrm{gL}^{-1}\right), \\
\text { peptone } \\
\left(0.6 \mathrm{gL}^{-1}\right) \\
\text { and yeast } \\
\text { extract } \\
\left(0.4 \mathrm{gL}^{-1}\right)\end{array}$ & 0.7 & $300-1200$ & 0.5 & $6.5-3.5 / 30$ & 0.09 & 15.00 & ND & [252] \\
\hline \multicolumn{10}{|c|}{ Cultivation of filamentous fungi in shake flasks } \\
\hline $\begin{array}{l}\text { Rhizopus } \\
\text { arrhizus }\end{array}$ & $\begin{array}{l}\text { Crude glycero } \\
\text { corn-steep li }\end{array}$ & $\begin{array}{l}(3 \%) \text { and } \\
\text { quor }(5 \%)\end{array}$ & 150 & ND & $5.5 / 28$ & 0.02 & 1.74 & 28.80 & [192] \\
\hline $\begin{array}{l}\text { Fusarium sp. } \\
\text { BS-8 }\end{array}$ & $\begin{array}{r}\text { Sucrose }(40 \mathrm{gl} \\
\text { yeast extract }\end{array}$ & $\begin{array}{l}-1) \text { and } \\
\left(0.8 \mathrm{gL}^{-1}\right)\end{array}$ & 150 & ND & $7.0 / 30$ & 0.01 & 2.43 & ND & {$[47]$} \\
\hline
\end{tabular}


Table 2 (continued)

\begin{tabular}{|c|c|c|c|c|c|c|c|c|c|}
\hline $\begin{array}{l}\text { Producer } \\
\text { microorgan- } \\
\text { ism }\end{array}$ & $\begin{array}{l}\text { Substrates } \\
(\mathrm{C} / \mathrm{N})\end{array}$ & $\begin{array}{l}\text { Working } \\
\text { volume } \\
\text { (L) }\end{array}$ & Mixing (rpm) & $\begin{array}{l}\text { Aeration } \\
\text { (vvm) }\end{array}$ & $\begin{array}{l}\mathrm{pH} / \text { tempera- } \\
\text { ture }\left({ }^{\circ} \mathrm{C}\right)\end{array}$ & $\begin{array}{l}\text { Volumetric } \\
\text { productivity } \\
\left(\mathrm{gL}^{-1} \mathrm{~h}^{-1}\right)\end{array}$ & $\begin{array}{l}\text { Maximum } \\
\text { yield } \\
\left(\mathrm{gL}^{-1}\right)\end{array}$ & $\begin{array}{l}\text { Surface } \\
\text { tension } \\
\left(\mathrm{mNm}^{-1}\right)\end{array}$ & References \\
\hline $\begin{array}{l}\text { Mucor hie- } \\
\text { malis }\end{array}$ & \multicolumn{2}{|c|}{$\begin{array}{l}\text { Soybean oil waste }(5 \%) \\
\text { sodium glutamate }(1 \%)\end{array}$} & 150 & ND & $\mathrm{ND} / 28$ & 0.08 & 7.73 & 32.00 & [208] \\
\hline $\begin{array}{l}\text { Aspergillus } \\
\text { niger }\end{array}$ & \multicolumn{2}{|c|}{$\begin{array}{l}\text { Banana stalk powder } \\
(5.75 \mathrm{~g}) \text {, yeast extract } \\
\left(1 \mathrm{gL}^{-1}\right) \\
\text { and peptone }\left(3 \mathrm{gL}^{-1}\right)\end{array}$} & ND & ND & $7.0 / 35$ & 0.03 & 5.50 & ND & [27] \\
\hline $\begin{array}{l}\text { Cunning- } \\
\text { hamella } \\
\text { echinulata }\end{array}$ & \multicolumn{2}{|c|}{$\begin{array}{l}\text { Soybean oil waste }(2 \%) \\
\text { and corn-steep liquor } \\
(8 \%)\end{array}$} & 150 & ND & $5.5 / 28$ & 0.04 & 5.18 & 31.70 & {$[251]$} \\
\hline
\end{tabular}

and yield close to these titres, and the other strains under these conditions showed lower productivity. Filamentous fungi normally require long periods to reach maximum production and show lower yield compared to yeasts.

Studies showed that high biosurfactants yields can be achieved through fed-batch bioreactor cultivation with online variables control (dissolved oxygen concentration, $\mathrm{pH}$ and temperature, etc.) and also for variables available offline (concentration of specific medium components, substrate, etc.) $[242,259]$. Changes in flow rates according to the feeding favour productivity and final yield [259]. Taking as an example the production of sophorolipids from S. bombicola, pulse feeding with biodiesel and glucose increased productivity to $1.55 \mathrm{gL}^{-1} \mathrm{~h}^{-1}$ compared to $0.40 \mathrm{gL}^{-1} \mathrm{~h}^{-1}$ when grown in shake flasks [239] and a productivity $1.45 \mathrm{gL}^{-1} \mathrm{~h}^{-1}$ was achieved by continuous feeding of hydrophobic substrate and with intermittent pulses of glucose [250]. In addition, an increase in yield (14\%) was achieved by propagating under fed batch conditions while exposing to ultrasonic waves, which is due to the phonophoretic effect that increases the permeability of the cell membrane and favours the absorption and conversion of nutrients [236]. Higher productivity $\left(1.59 \mathrm{gL}^{-1} \mathrm{~h}^{-1}\right)$ was achieved through semicontinuous cultivation with integrated two-stage separation processes compared to fed batch production $\left(1.25 \mathrm{gL}^{-1} \mathrm{~h}^{-1}\right)$ [257].

The inoculum is typically produced using pure cultures in media not necessarily the same as that used for production [260]. Bioprocesses for filamentous fungi are usually started with fungal spores which develop into hyphae branches and hyphal extensions to form structures called "pellets" [261]. The amount of inoculum supplied is about $3-10 \%$ of the working volume of the bioreactor, and it is expected that a larger volume can minimize the lag phase and produce a larger amount of biomass, which reduces the process time, consequently, the productivity of the bioreactor is increased [260]. Pre-treatments applied during inoculum preparation, such as application of an electric field after the development of Aspergillus brasiliensis spores in an electrochemical bioreactor, allowed the increase in production of bioemulsifier by $19.5 \%$ [194]. This was due to the fact that electric current promotes changes in the cell membrane and induces gene expression associated with the hydrophobin proteins that facilitates substrate uptake [194].

The ideal $\mathrm{pH}$ reported for biosurfactant production is slightly acid, preferably between 5 and 7 (Table 2). In some bioprocesses, the $\mathrm{pH}$ of the medium strongly influences biosurfactant production and the transport of various components across the cell membrane [55, 252]. The $\mathrm{pH}$ should be kept stable to avoid cell lysis, however, change in its value may trigger biosurfactant production, its value, however, is usually slightly reduced by the end of the cultivation [136, 252]. A strain of $A$. pullulans produced liamocins $\left(15 \mathrm{gL}^{-1}\right)$ only after decreasing the $\mathrm{pH}$ of the culture broth from 6.0 to 3.5 [252]. In addition, low $\mathrm{pH}$ prevents microbial contamination of the culture medium and favours its maintenance through longer fermentation times [145].

Biosurfactant production processes are typically aerobic, requiring high rates of aeration and mixing during submerged cultivation. To enhance oxygen transfer rate in sophorolipids production, a 2:1 height/diameter ratio of the bioreactors is recommended [242, 262]. However, there are no studies related to fungal biosurfactant production with chemical engineering parameters, such as oxygen transfer coefficient $\left(\mathrm{k}_{\mathrm{L}} \mathrm{a}\right)$. The effect of aeration rates has been less investigated as most studies are focused on the characterization and application of the molecules and not necessarily on the effects of aeration. Normally, dissolved oxygen is controlled between 25 and 50\% saturation [217, 250]. High rates of aeration can increase the formation of foam, which hinders the recovery of the biosurfactant and decreases its yield [231, 263].

The mixing of the culture medium ensures a more homogenized system in submerged cultures, its application in solid cultures using filamentous fungi is limited due to the high shear stress [24]. There are few reports related to the effect of mixing speed on biosurfactant production. Intermittent mixing of the solid medium cultivated with S. bombicola 
for SL production increased substrate bioavailability and process yield $(0.235 \mathrm{~g} / \mathrm{g})$ [220], possibly through minimizing mass/heat transfer problems. In submerged cultures for biosurfactants production carried out in agitation flasks, the mixture is performed by orbital agitation. Stirring speeds between 150 and $800 \mathrm{rpm}$ have been commonly reported for fungal biosurfactant production [153, 238, 250], speeds of about $150 \mathrm{rpm}$ are usual for filamentous strains to maintain cellular integrity and speeds above $200 \mathrm{rpm}$ are easily achieved in cultures of agitated bioreactors [152, 192]. High stirring speeds are required when there is an increase in viscosity concomitant with biosurfactant production, which limits oxygen transfer [250].

The optimum culture temperature for both yeast and filamentous fungi is typically within the mesophilic range of $25-30{ }^{\circ} \mathrm{C}$ (Table 2). This condition is advantageous for the industry since it does not increase costs related to the cooling stages of the culture medium [136]. However, the thermophilic fungi Fusarium fujikuroi produces trehalose lipids with lower surface tension $\left(20.08 \mathrm{mNm}^{-1}\right)$ at $47{ }^{\circ} \mathrm{C}$ [107] while psychotolerant yeasts isolated from cold environments produce biosurfactants at $20^{\circ} \mathrm{C}$ [155].

Moisture is an important parameter in solid-state cultivation, as it influences microbial growth rate on the substrates and determines the process yield. Fungal cultures require water activity around $0.5-0.6$ [55]. The ideal value for moisture depends on parameters such as size, porosity and composition of the substrate, as well as on the characteristics of the strains. Values between 45 and $75 \%$ have been reported for SL production from S. bombicola [220, 249].

\section{Experimental design and response surface methodology}

Statistical experimental designs allow the verification of the influence of multiple variables, individually or in relation to each other, and reduce the number of assays carried out. This method can indicate the most significant variables of the process and subsequently allow for optimizations [264].

The individual study of each independent variables $(\mathrm{pH}$, agitation, nutrients, inoculum size) that have an effect on biosurfactant production can be a first strategy for optimization [128]. Alternatively, when more than five independent variables are investigated, the Plackett-Burman model can be used to assess variables that influence the system. This approach allows for optimizations in the fractional or complete experimental designs [128, 265]. The use of fractional experimental designs for example showed that yeast extract $\left(2 \mathrm{gL}^{-1}\right)$ and wastewater from the olive oil industries $[1.5 \%(\mathrm{w} / \mathrm{w})]$ provided similar biosurfactant production by Aureobasidium thailandense as that of lauric acid ester [266].
The literature states that different parameters and components of the culture medium, when optimized by statistical models (response surface methodology), result in 1.65-4 times higher productivity compared to non-optimized media [6]. After optimizing the amount of substrate (waste cooking oil) and inoculum size through a central composite design for example, the yield of MEL by $P$. aphidis ZJUDM34 was sixfold higher $\left(61.50 \mathrm{gL}^{-1}\right)$ compared to the non-optimized medium $\left(10.25 \mathrm{gL}^{-1}\right)$ [267].

\section{Genetic and metabolic engineering, an emerging alternative}

An alternative to increase productivity and the development of new surfactants is through genetic improvements of strains $[11,23]$. Genetic material can be modified by random mutation or by metabolic engineering [158]. Although it is conceivable that random mutation from techniques such as exposure to UV radiation, chemical components and base analogues has enabled the selection of mutant strains for biosurfactant production [228], only a single study was published on the use of mutagenic agent in fungi. It was reported that after exposed to the chemical mutagen (ethidium bromide) Aspergillus niger increased its yield of biosurfactant production by $43 \%$ [27].

Since 2014, the US 8,911,982 B2 patent granted the company Evonik the right to produce sophorolipids from genetically modified $S$. bombicola through the insertion and deletion of genes that overexpress enzymes involved in the synthesis of those compounds [268]. The majority of the production was directed to acidic sophorolipids $\left(138 \mathrm{gL}^{-1}\right)$ through the deletion of the lactone esterase gene $(\Delta s b l e)$ in $S$. bombicola, restricting biosynthesis of the lactonic forms [269]. Another example is mono-acylated and deacetylated MEL-D production by the deletion of an acyltransferase gene (PtMAC2) in Pseudozyma tsukubaensis. This gene recombination allowed the production of new mannosylerythritol lipid derivatives, maximizing their applicability in the industry [270].

The production of new structural variants of biosurfactants expands their application. A good example is the Bolaform (sophorosides), a compound that consists of a long hydrophobic spacer with hydrophilic groups at both ends. These changes increase the molecule's solubility in water and the formation of micelles, thus improving the physico-chemical properties of the bioactive agent [271, 272]. The deletion of the acetyltransferase $(\Delta a t)$ and lactonase genes $(\Delta l a c)$ and the insertion of a second glycosyltransferase gene $(\Delta u g t b l)$ in $S$. bombicola promoted Bolaform product production [271]. In this context, the deletion of the putative alcohol oxidase gene faol from S. bombicola $(\Delta a t \Delta$ sble $\Delta$ faol) allowed the supply of fatty alcohols 
instead of fatty acids to the culture medium, favouring the production of Bolaform biosurfactant $\left(20 \mathrm{gL}^{-1}\right)$ [272].

Although the heterologous production of fungal biosurfactants in bacteria is an interesting alternative, since it is easier and faster, the production of hydrophobins in bacterial host presents very low yields $\left(10-100 \mathrm{mgL}^{-1}\right)$ and require additional steps for inclusion body purification such as denaturation/renaturation to recover the biosurfactant [140]. The yield in heterologous production of hydrophobin (330 $\mathrm{mgL}^{-1}$ ) in Pichia pastoris can be increased by 30 -fold through an increase of 3 copies of the overexpressed gene chaperone protein Ero1p and a tenfold increase with the overexpression of the gene $K A R 2$ encoding the endoplasmic reticulum resident chaperone protein [273]. The expression of hydrolytic enzymes, such as lipases, in biosurfactants producer fungi is a strategy for petroleum derivatives consumption. A 1.7-fold increase in MEL-B yield in a recombinant strain of $P$. tsukubaensi was achieved after the insertion of the lipase gene PaLIPAp (PaLIPA) from P. antarctica T-34 [274]. In addition, Saccharomyces cerevisiae were also used as an expression vector to produce rhamnolipids (a bacterial biosurfactants) through the insertion of genes from Pseudomonas aeruginosa [275] and sophorolipids from the expression of the glycosyltransferase $(g t f-1)$ gene from $C$. bombicola [276]. This approach promoted glycosylation of lipids and increased the spectrum for use of substrates (including sterols) [276].

Metabolic flow analysis between wild and mutant strains of $S$. bombicola showed that an inadequate supply of intracellular acetyl-CoA in the mutant strain, as well as citrate metabolism, can negatively affect sophorolipids biosynthesis, since it is related to fatty acid metabolism [277]. However, the regulatory mechanisms that determine genomic analysis and attempts to induce the overproduction of biosurfactants can only be explored in a restricted way due to the wide structural variety of these molecules and biosynthesis pathways involved in production [156]. The application of advanced tools in genomics, transcriptomics, proteomics and metabolomics to elucidate complete biosynthetic pathways and their regulation in biosurfactant-producing strains, improves our understanding of the bottle necks in synthesis pathways of some metabolites, diverting most of the energy to the main metabolic pathways involved in the production of biosurfactant [171].

\section{Biosurfactant downstream processing}

\section{Recovery and purification}

The structural diversity of biosurfactants and their unknown thermodynamic data present additional challenges in relation to their recovery. Different molecular characteristics, such as location, ionic charge and solubility, significantly influence their recovery and purification [23, 278]. In general, downstream processing depends on biosurfactant itself and the purity required for application.

Biosurfactants associated with fungal cell membrane (or intracellular) require cell lysis or sonication to be released [279]. Application of ultrasound in biosurfactant recovery produced by Fusarium proliferatum increased the yield by $30 \%$ before extraction with a solvent [280]. On the other hand, when biosurfactants are already excreted in the medium, the fungal biomass can be separated by filtration and/or centrifugation, which allows better conditions for recovery of the bioproduct [208].

The recovery of extracellular biosurfactants includes acid precipitation with hydrochloric acid [281] followed by solvent extraction (ethyl acetate, acetone, ethanol) to remove lipid contaminants or residual carbohydrate compounds $[110,251]$. The economic advantage of this process is the possibility to recover the solvent. An MEL recovery system (94\% efficient) was developed by combining the following solvents: methanol/water/n-hexane ( $\mathrm{pH}$ 2) [282].

The separation processes with membranes such as microfiltration and ultrafiltration are used to recover biosurfactants [63]. Ultrafiltration processes with high molecular weight membranes $(100 \mathrm{kDa})$ facilitate the recovery and increase biosurfactants purity, which can be extended with a crossflow filtration unit. At concentrations above CMC, biosurfactants increase their molecular weight due to the property of self-aggregation, forming micelles that favours retention in the membrane [28].

Several techniques, in particular foam fractionation, gravity separation and membrane separation, have been shown to be effective in the recovery of biosurfactants, since these techniques can become useful to avoid problems caused by product accumulation in the medium [29]. Furthermore, the integrated production and recovery of sophorolipids can be industrially promising, since it allowed the extension of the process time $(480 \mathrm{~h})$ with $93 \%$ efficiency in six separation cycles, reducing the probability of contamination and avoiding the addition of chemicals [283].

The production and integrated gravitational separation of biosurfactants allow continuous recovery of sophorolipids (86-280 g) of higher or lower density than the culture medium, while medium broth and cells are recirculated. This system provides reductions of up to $11 \%$ in the volume of the bioreactor [284]. An integrated system for the production and separation of sophorolipids by gravity in a bioreactor with double ventilation tubes and double sieve plates has been proposed [257]. The two-stage recovery system improved the purity of the sophorolipids by $23.3 \%$, allowing the recycling of substrates and yeast cells, minimizing inhibition processes and increasing substrate rate consumption [257]. 
Foam fractionation is another integrated technology that enable the continuous recovery of extracellular hydrophobins $(70 \%)$ from the culture medium in a recirculation system, as a possibility to minimize the uncontrolled foaming in bioreactors, while recovering the enriched biosurfactant produced [285]. However, these approaches are largely inefficient and are not yet feasible for industrial applications. For example, foam fractionation is only suitable for the separation of biosurfactants at very low concentrations and the membrane separation is limited by incrustations on the membrane $[28,282,286]$.

Other techniques can also be applied such as adsorption chromatography [71], lyophilization [165, 210] and crystallization [287, 288] which provides greater purity and stability for storage of the molecule. It is important to note that downstream costs related to biosurfactant production can represent up to $80 \%$ out of total cost [289, 290], but purification steps can be reduced depending on the purity required for biosurfactant application.

\section{Structural and ionic characterization}

Biosurfactant characterisation is an important step in experimental studies, as it allows the discovery of new chemical structures and to analyse the influence of the substrate on its structure $[214,239]$, as well as elucidating structures with accuracy which helps determining potential applications. Only higher resolution techniques, such as spectroscopy and spectrometry, can correctly determine the structures of various biosurfactant congeners.

The combination of Thin Layer Chromatography (TLC) with Fourier Transform Infrared (FTIR) spectroscopy can enable a partial characterization of biosurfactants [153].
FTIR clarifies the different basic functional groups (alkyls, carbonyls and esters) of biosurfactants based on molecular vibrations at specific wavelengths [291]. A series of Nuclear Magnetic Resonance (NMR) spectroscopy experiments enable the accurate identification of each functional group, as well as the position of the bonds in the carbohydrate and lipid molecules. This technique can differentiate the structural isomers of the same molecule and analyse the purity of the sample [292].

The Mass Spectrometry (EM) provides molecular weight of the biosurfactant, i.e., the technique requires extremely purified biosurfactants [132, 210]. The molecular mass obtained by this procedure can be combined with the results provided by Gas Chromatography (GC) to determine the side chain compositions of the fatty acids present in the biosurfactant [293], a technique commonly called Mass Spectrometry coupled to Gas Chromatography (GC-MS) [254]. On the other hand, the hydrophilic portion is commonly characterized by High Performance Liquid Chromatography (HPLC) [239].

Matrix-Assisted Laser Desorption Ionization Time of Light Mass Spectrometry- (MALDI-TOF-MS) is a technique highly sensitive due to its smooth ionization capacity and suitability for high molecular weight biosurfactants (polar and non-polar) [292]. The use of MALDI-TOF-MS remain restricted due to its high costs [23] and, when associated with NMR and GC-MS and/or with HPTLC and GC, it is effective in distinguishing individual variants of MEL for example [29, 87].

The double diffusion agar test is a simple technique to determine the ionic charge of biosurfactants (Fig. 9), as reported by several authors [132, 135, 293]. The qualitative result is obtained through visual inspection and validated by
Fig. 9 The double diffusion agar test occurs with the addition of biosurfactant samples in wells in a row regularly spaced against another row of wells filled with a known cationic or anionic element. The appearance of precipitation lines $(48 \mathrm{~h})$ between the wells indicates the ionic character of the biosurfactants

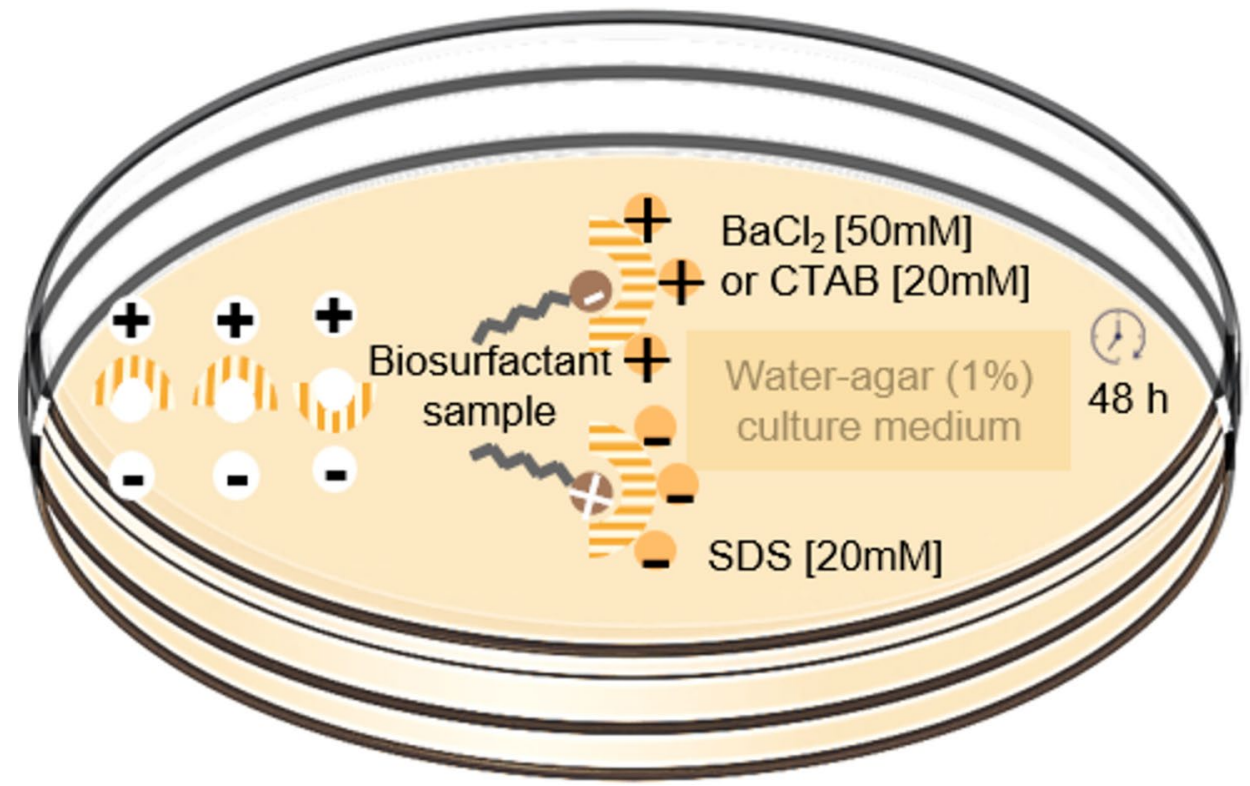


the electrokinetic technique (zeta potential), where the surface charge of the molecule is determined by measuring the repulsion between the hydrophilic parts of the biosurfactant $[51,251,254]$.

\section{Biotechnological applications in commercial product formulation}

Several companies already sell products containing SL and MEL in their composition. The Asian company Allied Carbon Solutions Co., Ltd (Japan) is a reference in the production and commercialization of SL on a large scale $(\approx$ 1000L). Other Asian companies such as Toyobo and Saraya Co. (Japan), Kanebo Cosmetics Inc (Japan) and MG Intobio Co., Ltd (South Korea) market personal care products containing MEL and SL. In Europe, the German companies Evonik, Ecover and Henkel produce and/or market SL and MEL, respectively, in detergents and cleaning products. Likewise, the companies Givaudan SA (France) and Holiferm Technology (UK) produce and apply SL in cosmetic formulations.

The formulation of personal care products such as toothpastes and mouthwashes containing biosurfactants were proposed using produced from S. bombicola [294, 295]. The toothpastes also contained chitosan extracted from Mucorales and showed no toxicity, as well as, showed desirable characteristics, such as $\mathrm{pH}$ around 9 , foaming ability (63-95\%), and inhibition of cell viability of the cariogenic bacteria Streptococcus mutans [295].

Biosurfactants produced by $C$. lipolytica and C. bombicola together with potassium sorbate (chemical preservative) were active ingredients in product formulations for hydrophobic pollutant remediation [296, 297]. These formulations maintained their surfactant properties and stability for 90 days at sufficient level to ensure their application as a dispersant [296, 297]. The minimum shelf life required for commercialization is typically 120 days [296, 297]. An alternative for increasing biosurfactants shelf life is drying by atomization. The absence of water promotes greater stability and preservation, although it increases costs [298]. The storage of liquid/powder sophorolipids is usually carried out in polyethylene packaging such as bags, bottles, drums and containers, these biosurfactants have pale yellow to brown coloration.

Biosurfactants produced by Candida utilis were tested for possible uses in the food sector to formulate salad dressings and mayonnaise, this ingredient provided physico-chemical stability in temperature and acidity variations during food processing [299, 300]. Detergents containing biosurfactant produced from Cunninghamella echinulata has also been tested for use in the chemical-textile industry, as they promoted cleaning and removal of motor oil ( $86 \%)$ in cotton fabric, maintaining the stability of the structural integrity of the fibre [254]. The use of biosurfactants in biomedical, therapeutic and pharmaceutical application have been recently reviewed highlighting potential applications in cleaning handwash formulations and plastic and fabric surface coating agents useful for combating microbial infections [301].

Some tests for potential fungal biosurfactant uses in applied to public health applications have also been tested. Biosurfactants produced from Scheffersomyces stipites [281] and Wickerhamomyces anomalus [71] promoted the death of larval exoskeletons of the Aedes aegypti mosquito after $12 \mathrm{~h}$ and $24 \mathrm{~h}$, respectively, showing their potential in larvicidal formulations against dengue arbovirus vector. The commercial formulations reported here for the several applications did not show toxic effects, except for larvicidal activity (not analyzed).

\section{Conclusions}

Nature provides enormous possibilities to isolate biosurfactant-producing fungi that colonize diverse environments. The fungal bioprospecting for biosurfactant production has allowed the discovery of strains not yet described in the literature, as well as new molecular structures with surfactant action. However, bioprospecting based on metagenomic data still represents an untapped potential. Likewise, there is still a gap in relation to molecular methods intended for the screening of biosurfactant-producing organisms.

Economic issues and low process productivity are the main challenges to overcome fungal biosurfactant largescale production. Although several energy sources are promising for biosurfactant production, the economic viability to use waste streams can only be obtained with careful analysis between cost minimization and low yield due to the formation of inhibitory compounds. Changes in carbon/nitrogen sources and recombinant strains can produce biosurfactants with new and different chemical structures that ensure better physico-chemical properties for wider applications. Statistical and bioprocess tools applied to this biomolecule can result in achieving higher yields/productivity as well as better overall operational processes.

Sophorolipids and mannosylerythritol lipids are the main fungal biosurfactants investigated studied through process development to applications, both molecules are yeast products. Filamentous fungi biosurfactants have received less attention and were more focused on isolation and bioprospection, which allowed the identification of new species, some of which are able to produce trehalose lipids (not yet described for eukaryotes) and lipopeptides (previously only observed in yeast). Few other studies with filamentous are restricted to the influence and optimization of nutritional conditions, production in association with other metabolites, 
and applications for environmental remediation, textile and cleaning. In general, fungal biosurfactants have wide applicability and have already been formulated as ingredients for several commercial products, which probably opens new windows for future studies aimed at their inclusion in various sectors of different market segments.

Acknowledgements The authors would like to acknowledge the Bioprocess and Biotechnology Engineering Degree at the Federal University of Tocantins-BR and the Graduate Program in Biotechnology and Biosciences at the Federal University of Santa Catarina-BR for promoting the professional qualification of the first author.

\section{Declarations}

Conflict of interest The authors declare no financial or commercial conflict of interest.

\section{References}

1. Cowan-Ellsberry C, Belanger S, Dorn P, Dyer S, McAvoy D, Sanderson H et al (2014) Environmental safety of the use of major surfactant classes in North America. Crit Rev Environ Sci Technol 44:1893-1993. https://doi.org/10.1080/10739149.2013. 803777

2. Scott MJ, Jones MN (2000) The biodegradation of surfactants in the environment. Biochim Biophys Acta-Biomembr 1508:235251. https://doi.org/10.1016/s0304-4157(00)00013-7

3. Otzen DE (2017) Biosurfactants and surfactants interacting with membranes and proteins: same but different? Biochim Biophys Acta Biomembr 1859:639-649. https://doi.org/10.1016/j. bbamem.2016.09.0244

4. Johnson P, Trybala A, Starov V, Pinfield VJ (2021) Effect of synthetic surfactants on the environment and the potential for substitution by biosurfactants. Adv Colloid Interface Sci 288:102340. https://doi.org/10.1016/j.cis.2020.102340

5. Çelik PA, Manga EB, Çabuk A, Banat IM (2020) Biosurfactants' potential role in combating COVID-19 and similar future microbial threats. Appl Sci 11:334. https://doi.org/10.3390/app11 010334

6. Geetha SJ, Banat IM, Joshi SJ (2018) Biosurfactants: Production and potential applications in microbial enhanced oil recovery (MEOR). Biocatal Agric Biotechnol 14:23-32. https://doi.org/ 10.1016/j.bcab.2018.01.010

7. Industries E (2020) Evonik and Unilever team up for large-scale production of world's first 'green' biosurfactant. Focus Surfactants 2:3. https://doi.org/10.1016/j.fos.2020.02.010

8. Marchant R, Banat IM (2012) Biosurfactants: a sustainable replacement for chemical surfactants? Biotechnol Lett 34:15971605. https://doi.org/10.1007/s10529-012-0956-X

9. Marchant R, Banat IM (2012) Microbial biosurfactants: challenges and opportunities for future exploitation. Trends Biotechnol 30:558-565. https://doi.org/10.1016/j.tibtech.2012.07.003

10. Raaijmakers JM, De Bruijn I, Nybroe O, Ongena M (2012) Natural functions of lipopeptides from Bacillus and Pseudomonas : more than surfactants and antibiotics. FEMS Microbiol Rev 34:1037-1062. https://doi.org/10.1111/j.1574-6976.2010. 00221.x

11. Abdel-Mawgoud AM, Stephanopoulos G (2018) Simple glycolipids of microbes: chemistry, biological activity and metabolic engineering. Synth Syst Biotechnol 3:3-19. https://doi.org/10. 1016/j.synbio.2017.12.001

12. Garay LA, Sitepu IR, Cajka T, Xu J, Teh HE, German JB et al (2018) Extracellular fungal polyol lipids: a new class of potential high value lipids. Biotechnol Adv 36:397-414. https://doi.org/ 10.1016/j.biotechadv.2018.01.003

13. Sunde M, Pham CLL, Kwan AH (2017) Molecular characteristics and biological functions of surface-active and surfactant proteins. Annu Rev Biochem 86:585-608

14. Bae I, Lee ES, Yoo JW, Lee SH, Ko JY, Kim YJ et al (2018) Mannosylerythritol lipids inhibit melanogenesis via suppressing ERK-CREB-MiTF-tyrosinase signalling in normal human melanocytes and a three-dimensional human skin equivalent. Exp Dermatol 28:738-741. https://doi.org/10.1111/exd.13836

15. Chieregato MB, Laroque DA, de Andrade LM, Carciofi BAM, Tenório JAS, de Andrade CJ (2019) Production of active cassava starch films; effect of adding a biosurfactant or synthetic surfactant. React Funct Polym 144:104368. https://doi.org/10. 1016/j.reactfunctpolym.2019.104368

16. Shah V, Daverey A (2021) Effects of sophorolipids augmentation on the plant growth and phytoremediation of heavy metal contaminated soil. J Clean Prod 280:124406. https://doi.org/10. 1016/j.jclepro.2020.124406

17. Chuo SC, Ahmad A, Mohd-Setapar SH, Mohamed SF, Rafatullah M (2019) Utilization of green sophorolipids biosurfactant in reverse micelle extraction of antibiotics: Kinetic and mass transfer studies. J Mol Liq 276:225-232. https://doi.org/10.1016/j. molliq.2018.11.138

18. Guerfali M, Ayadi I, Mohamed N, Ayadi W, Belghith H, Bronze MR et al (2019) Triacylglycerols accumulation and glycolipids secretion by the oleaginous yeast Rhodotorula babjevae Y-SL7 Structural identification and biotechnological applications. Bioresour Technol 273:326-334. https://doi.org/10.1016/j.biort ech.2018.11.036

19. Ranjana M, Ramesh VVE, Satheesh Babu TG, Kumar DVR (2019) Sophorolipid induced hydrothermal synthesis of $\mathrm{Cu}$ nanowires and its modulating effect on $\mathrm{Cu}$ nanostructure. Nano Struct Nano Objects 18:100285. https://doi.org/10.1016/j. nanoso.2019.100285

20. Menon V, Prakash G, Prabhune A, Rao M (2010) Biocatalytic approach for the utilization of hemicellulose for ethanol production from agricultural residue using thermostable xylanase and thermotolerant yeast. Bioresour Technol 101:5366-5373. https:// doi.org/10.1016/j.biortech.2010.01.150

21. Ye M, Sun M, Wan J, Feng Y, Zhao Y, Tian D et al (2016) Feasibility of lettuce cultivation in sophoroliplid-enhanced washed soil originally polluted with $\mathrm{Cd}$, antibiotics, and antibiotic-resistant genes. Ecotoxicol Environ Saf 124:344-350. https://doi.org/ 10.1016/j.ecoenv.2015.11.013

22. Luna JM, Rufino RD, Maria A, Jara AT, Brasileiro PPF, Sarubbo LA (2015) Environmental applications of the biosurfactant produced by Candida sphaerica cultivated in low-cost substrates. Colloids surfaces a Physicochem. Eng Asp 480:413-418. https:// doi.org/10.1016/j.colsurfa.2014.12.014

23. Jimoh AA, Lin J (2019) Biosurfactant: a new frontier for greener technology and environmental sustainability. Ecotoxicol Environ Saf 184:109607. https://doi.org/10.1016/j.ecoenv.2019.109607

24. Bajpai P (2020) Bioprocesses in industrial biotechnology, In: Biotechnology in the Chemical Industry, Elsevier, pp 37-56. https://doi.org/10.1016/B978-0-12-818402-8.00005-7

25. Walter V, Syldatk C, Hausmann R (2010) Screening concepts for the isolation of Biosurfactant producing microorganisms In: biosurfactants. Adv Exp Med Biol 672:1-13. https://doi.org/10. 1007/978-1-4419-5979-9_1 
26. Geys R, Soetaert W, Van Bogaert I (2014) Biotechnological opportunities in biosurfactant production. Curr Opin Biotechnol 30:66-72. https://doi.org/10.1016/j.copbio.2014.06.002

27. Asgher M, Arshad S, Ahmad S, Nimrah Q (2020) Improved biosurfactant production from Aspergillus niger through chemical mutagenesis: characterization and RSM optimization. SN Appl Sci 2:1-11. https://doi.org/10.1007/s42452-020-2783-3

28. de Andrade CJ, de Andrade LM, Rocco SA, Sforça ML, Pastore GM, Jauregi P (2017) A novel approach for the production and purification of mannosylerythritol lipids (MEL) by Pseudozyma tsukubaensis using cassava wastewater as substrate. Sep Purif Technol 180:157-167. https://doi.org/10.1016/j.seppur.2017.02. 045

29. Dolman BM, Wang F, Winterburn JB (2019) Integrated production and separation of biosurfactants. Process Biochem 83:1-8. https://doi.org/10.1016/j.procbio.2019.05.002

30. Mulligan CN (2005) Environmental applications for biosurfactants. Environ Pollut 133:183-198. https://doi.org/10.1016/j. envpol.2004.06.009

31. Uzoigwe C, Burgess JG, Ennis CJ, Rahman PKSM (2015) Bioemulsifiers are not biosurfactants and require different screening approaches. Front Microbiol 6:1-6. https://doi.org/10.3389/ fmicb.2015.00245

32. Perfumo A, Smyth TJP, Marchant R, Banat IM (2010) Production and roles of biosurfactants and Bioemulsifiers in accessing hydrophobic substrates. In: Timmis KN (ed) Handbook of hydrocarbon and lipid microbiology. Springer, Berlin, pp 1501-1512

33. Mukhopadhyay SK, Chatterjee S, Gauri SS, Das SS, Mishra A, Patra M et al (2014) Isolation and characterization of extracellular polysaccharide Thelebolan produced by a newly isolated psychrophilic Antarctic fungus Thelebolus. Carbohydr Polym 104:204-212. https://doi.org/10.1016/j.carbpol.2014.01.034

34. Jahan R, Bodratti AM, Tsianou M, Alexandridis P (2020) Biosurfactants, natural alternatives to synthetic surfactants: physicochemical properties and applications. Adv Colloid Interface Sci 275:102061. https://doi.org/10.1016/j.cis.2019.102061

35. Banat IM, Franzetti A, Gandolfi I, Bestetti G, Martinotti MG, Fracchia L et al (2010) Microbial biosurfactants production, applications and future potential. Appl Microbiol Biotechnol 87:427-444. https://doi.org/10.1007/s00253-010-2589-0

36. Lu H, Pezron I, Gaudin T, Drelich A (2018) Non-equilibrium micelles formed by sugar-based surfactants under their Krafft temperature. Coll Surf Physicochem Eng Asp 540:167-176. https://doi.org/10.1016/j.colsurfa.2017.12.053

37. Sałek K, Euston SR (2019) Sustainable microbial biosurfactants and bioemulsifiers for commercial exploitation. Process Biochem 85:143-155. https://doi.org/10.1016/j.procbio.2019.06.027

38. Pessôa MG, Vespermann KAC, Paulino BN, Barcelos MCS, Pastore GM, Molina G (2019) Newly isolated microorganisms with potential application in biotechnology. Biotechnol Adv 37:319-339. https://doi.org/10.1016/j.biotechadv.2019.01.007

39. Kitamoto D, Morita T, Fukuoka T, Konishi M, Imura T (2009) Self-assembling properties of glycolipid biosurfactants and their potential applications. Curr Opin Colloid Interface Sci 14:315328. https://doi.org/10.1016/j.cocis.2009.05.009

40. Eldin AM, Kamel Z, Hossam N (2019) Isolation and genetic identification of yeast producing biosurfactants, evaluated by different screening methods. MicroChem J 146:309-314. https:// doi.org/10.1016/j.microc.2019.01.020

41. Ishaq U, Akram MS, Iqbal Z, Rafiq M, Akrem A, Nadeem M et al (2015) Production and characterization of novel self-assembling biosurfactants from Aspergillus flavus. J Appl Microbiol 119:1035-1045. https://doi.org/10.1111/jam.12929

42. Camargo-De-Morais MM, Ramos SAF, Pimentel MCB, De Morais MA, Lima Filho JL (2003) Production of an extracellular polysaccharide with emulsifier properties by Penicillium citrinum. World J Microbiol Biotechnol 19:191-194. https://doi. org/10.1023/A:1023299111663

43. Kiran GS, Hema TA, Gandhimathi R, Selvin J, Thomas TA, Rajeetha Ravji T et al (2009) Optimization and production of a biosurfactant from the sponge-associated marine fungus Aspergillus ustus MSF3. Coll Surf B Biointerfaces 73:250-256. https://doi.org/10.1016/j.colsurfb.2009.05.025

44. Radha P, Suhazsini P, Prabhu K, Jayakumar A, Kandasamy R (2020) Chicken tallow, a renewable source for the production of Biosurfactant by Yarrowia lipolytica MTCC9520, and its application in Silver Nanoparticle synthesis. J Surfactants Deterg 23:119-135. https://doi.org/10.1002/jsde. 12357

45. Gautam G, Mishra V, Verma P, Pandey AK, Negi SA (2014) Cost effective strategy for production of Bio-surfactant from locally isolated Penicillium chrysogenum SNP5 and its applications. J Bioprocess Biotech 4:1-7. https://doi.org/10.4172/2155-9821. 1000177

46. Bills GF, Yue Q, Chen L, Li Y, An Z, Frisvad JC (2016) Aspergillus mulundensis sp. nov., a new species for the fungus producing the antifungal echinocandin lipopeptides, mulundocandins. J Antibiot 69:141-148. https://doi.org/10.1038/ja.2015.105

47. Qazi MA, Kanwal T, Jadoon M, Ahmed S (2014) Isolation and characterization of a Biosurfactant-producing Fusarium sp. BS-8 from oil contaminated soil. Biotechnol Prog 30:1065-1075. https://doi.org/10.1002/btpr.1933

48. Cirigliano MC, Carman GM (1984) Isolation of a bioemulsifier from Candida lipolytica. Appl Environ Microbiol 48:747-750. https://doi.org/10.1128/AEM.48.4.747-750.1984

49. Cameron DR, Cooper DG, Neufeld RJ (1988) The Mannoprotein of Saccharomyces cerevisiae is an effective Bioemulsifier. Appl Environ Microbiol 54:1420-1425

50. Lukondeh T, Ashbolt NJ, Rogers PL (2003) Evaluation of Kluyveromyces marxianus FII 510700 grown on a lactosebased medium as a source of a natural bioemulsifier. J Ind Microbiol Biotechnol 30:715-720. https://doi.org/10.1007/ s10295-003-0105-6

51. Amaral PFF, da Silva JM, Lehocky M, Barros-Timmons AMV, Coelho MAZ, Marrucho IM et al (2006) Production and characterization of a bioemulsifier from Yarrowia lipolytica. Process BioChem 41:1894-1898. https://doi.org/10.1016/j.procbio.2006. 03.029

52. Kim Y-B, Yun HS, Kim E (2009) Enhanced sophorolipid production by feeding-rate-controlled fed-batch culture. Bioresour Technol 100:6028-6032. https://doi.org/10.1016/j.biortech.2009. 06.053

53. Paulino BN, Pessôa MG, Mano MCR, Molina G, Neri-Numa IA, Pastore GM (2016) Current status in biotechnological production and applications of glycolipid biosurfactants. Appl Microbiol Biotechnol 100:10265-10293. https://doi.org/10.1007/ s00253-016-7980-z

54. Kulakovskaya E, Baskunov B, Zvonarev A (2014) The antibiotic and membrane-damaging activities of cellobiose lipids and sophorose lipids. J Oleo Sci 63:701-707. https://doi.org/10.5650/ jos.ess 14037

55. Banat IM, Carboué Q, Saucedo-Castañeda G, de Jesús C-M (2021) Biosurfactants: the green generation of speciality chemicals and potential production using Solid-State fermentation (SSF) technology. Bioresour Technol 320:124222. https://doi. org/10.1016/j.biortech.2020.124222

56. Lydon HL, Baccile N, Callaghan B, Marchant R, Mitchell CA, Banat IM (2017) Adjuvant antibiotic activity of acidic Sophorolipids with potential for facilitating wound healing. Antimicrob Agents Chemother 61:e02547-e2616. https://doi.org/10. 1128/AAC.02547-16

57. Claus S, Van Bogaert INA (2017) Sophorolipid production by yeasts: a critical review of the literature and suggestions for 
future research. Appl Microbiol Biotechnol 101:7811-7821. https://doi.org/10.1007/s00253-017-8519-7

58. Delbeke EIP, Van Geem KM, Stevens C V, Van Bogaert INA (2018) Sophorolipid Modification: The Power of Yeasts and Enzymes In: Lipid Modification by Enzymes and Engineered Microbes. Elsevier 315-341. https://doi.org/10.1016/B978-0-12813167-1/00014-1

59. Jadhav JV, Pratap AP, Kale SB (2019) Evaluation of sun flower oil re fi nery waste as feedstock for production of sophorolipid. Process Biochem 78:15-24. https://doi.org/10.1016/j.procbio. 2019.01.0151

60. Wang H, Roelants SLKW, To MH, Patria RD, Kaur G, Lau NS et al (2019) Starmerella bombicola : recent advances on sophorolipid production and prospects of waste stream utilization. J Chem Technol Biotechnol 94:999-1007. https://doi.org/ $10.1002 /$ jctb. 5847

61. Cortés-Sánchez ADJ, Hernández-Sánchez H, Jaramillo-Flores ME (2013) Biological activity of glycolipids produced by microorganisms: new trends and possible therapeutic alternatives. Microbiol Res 168:22-32. https://doi.org/10.1016/j.micRes2012. 07.002

62. Naughton PJ, Marchant R, Naughton V, Banat IM (2019) Microbial biosurfactants: current trends and applications in agricultural and biomedical industries. J Appl Microbiol 127:12-28. https:// doi.org/10.1111/jam.14243

63. Dhar P, Havskjold H, Thornhill M, Roelants S, Soetaert W, Kota HR et al (2021) Toward green flotation: Interaction of a sophorolipid biosurfactant with a copper sulfide. J Colloid Interface Sci 585:386-399. https://doi.org/10.1016/j.jcis.2020.11.079

64. Shah V, Doncel GF, Seyoum T, Eaton KM, Zalenskaya I, Hagver $\mathrm{R}$ et al (2005) Sophorolipids, microbial glycolipids with antihuman immunodeficiency virus and sperm-immobilizing activities. Antimicrob Agents Chemother 49:4093-4100. https://doi. org/10.1128/AAC.49.10.4093-4100.2005

65. VanBogaert INA, Zhang J, Soetaert W (2011) Microbial synthesis of sophorolipids. Process Biochem 46:821-833. https://doi. org/10.1016/j.procbio.2011.01.010

66. Elshikh M, Moya-Ramírez I, Moens H, Roelants S, Soetaert W, Marchant R et al (2017) Rhamnolipids and lactonic sophorolipids: natural antimicrobial surfactants for oral hygiene. J Appl Microbiol 123:1111-1123. https://doi.org/10.1111/jam.13550

67. Garg M, Priyanka CM (2018) Isolation, characterization and antibacterial effect of biosurfactant from Candida parapsilosis. Biotechnol Reports 18:e0251. https://doi.org/10.1016/j.btre. 2018.e00251

68. De Rienzo MAD, Dolman B, Guzman F, Kaisermann C, Winterburn J, Banat IM et al (2014) Antimicrobial properties of sophorolipids produced by Candida Bombicola ATCC 22214 against gram positive and Gram-negative bacteria. N Biotechnol 31:S66-S67. https://doi.org/10.1016/j.nbt.2014.05.1764

69. Ceresa C, Fracchia L, Williams M, Banat IM, Díaz De Rienzo MA (2020) The effect of sophorolipids against microbial biofilms on medical-grade silicone. J Biotechnol 309:34-43. https://doi. org/10.1016/j.jbiotec.2019.12.019

70. Sen S, Borah SN, Bora A, Deka S (2017) Production, characterization, and antifungal activity of a biosurfactant produced by Rhodotorula babjevae YS3. Microb Cell Fact 16:95. https://doi. org/10.1186/s12934-017-0711-z

71. de Fernandes NAT, deSouzaSimõesReisSouzaSchwan ACLAGMFKTRF et al (2020) Eco-friendly biosurfactant from Wickerhamomyces anomalus CCMA 0358 as larvicidal and antimicrobial. Microbiol Res 241:126571. https://doi.org/10.1016/j.micRe s2020.126571

72. Silveira VAI, Nishio EK, Freitas CAUQ, Amador IR, Kobayashi RKT, Caretta T et al (2019) Production and antimicrobial activity of sophorolipid against Clostridium perfringens and
Campylobacter jejuni and their additive interaction with lactic acid. Biocatal Agric Biotechnol 21:101287. https://doi.org/10. 1016/j.bcab.2019.101287

73. Silveira VAI, Marim BM, Hipólito A, Gonçalves MC, Mali S, Kobayashi RKT et al (2020) Characterization and antimicrobial properties of bioactive packaging films based on polylactic acid-sophorolipid for the control of foodborne pathogens. Food Packag Shelf Life 26:100591. https://doi.org/10.1016/j.fps1.2020. 10059

74. Daverey A, Pakshirajan K (2010) Sophorolipids from Candida bombicola using mixed hydrophilic substrates: production, purification and characterization. Coll Surf B Biointerfaces 79:246253. https://doi.org/10.1016/j.colsurfb.2010.04.002

75. Gaur VK, Regar RK, Dhiman N, Gautam K, Srivastava JK, Patnaik S et al (2019) Biosynthesis and characterization of sophorolipid biosurfactant by Candida spp: application as food emulsifier and antibacterial agent. Bioresour Technol 285:121314. https://doi.org/10.1016/j.biortech.2019.121314

76. Ozdener MH, Ashby RD, Jyotaki M, Elkaddi N, Spielman AI, Bachmanov AA et al (2019) Sophorolipid Biosurfactants activate taste receptor Type 1 member 3-mediated taste responses and block responses to bitter taste in vitro and in vivo. J Surfactants Deterg 22:441-449. https://doi.org/10.1002/jsde.12246

77. Sieverding E (2017) Increasing yields by the use of sophorolipids-US 2017/0094968 A1 https://patents.google.com/patent/ EP3142490A1/en

78. Baccile N, Noiville R, Stievano L, Van BI (2013) Sophorolipidsfunctionalized iron oxide nanoparticles. Phys Chem Chem Phys 15:1606-1620. https://doi.org/10.1039/c2cp41977g

79. Kasture M, Singh S, Patel P, Joy PA, Prabhune AA, Ramana CV et al (2007) Multiutility Sophorolipids as nanoparticle capping agents: synthesis of stable and water dispersible Co Nanoparticles. Langmuir 23:11409-11412. https://doi.org/10.1021/la702 931j

80. Helle SS, Duff SJB, Cooper DG (1993) Effect of surfactants on cellulose hydrolysis. Biotechnol Bioeng 42:611-617. https://doi. org/10.1002/bit.260420509

81. Fan L, Dong YC, Fan YF, Zhang J, Chen QH (2014) Production and identification of mannosylerythritol lipid-A homologs from the ustilaginomycetous yeast Pseudozyma aphidis ZJUDM34. Carbohydr Res 392:1-6. https://doi.org/10.1016/j.carRes2014. 04.013

82. Alimadadi N, Soudi MR, Talebpour Z (2018) Efficient production of tri-acetylated mono-acylated mannosylerythritol lipids by Sporisorium sp. aff. sorghi SAM20. J Appl Microbiol 124:457468. https://doi.org/10.1111/jam.13642

83. Morita T, Ogura Y, Takashima M, Hirose N, Fukuoka T, Imura $T$ et al (2011) Isolation of Pseudozyma churashimaensis sp. nov, a novel ustilaginomycetous yeast species as a producer of glycolipid biosurfactants, mannosylerythritol lipids. J Biosci Bioeng 112:137-144. https://doi.org/10.1016/j.jbiosc.2011.04.008

84. Niu Y, Fan L, Gu D, Wu J, Chen Q (2017) Characterization, enhancement and modelling of mannosylerythritol lipid production by fungal endophyte Ceriporia lacerate CHZJU. Food Chem 228:610-617. https://doi.org/10.1016/j.foodChem2017.02.042

85. Yu M, Liu Z, Zeng G, Zhong H, Liu Y, Jiang Y et al (2015) Characteristics of mannosylerythritol lipids and their environmental potential. Carbohydr Res 407:63-72. https://doi.org/10.1016/j. carRes2014.12.012

86. Beck A, Haitz F, Grunwald S, Preuss L, Rupp S, Zibek S (2019) Influence of microorganism and plant oils on the structure of mannosylerythritol lipid (MEL) biosurfactants revealed by a novel thin layer chromatography mass spectrometry method. J Ind Microbiol Biotechnol 46:1191-1204. https://doi.org/10.1007/ s10295-019-02194-2 
87. Rodrigues LR (2015) Microbial surfactants: fundamentals and applicability in the formulation of nano-sized drug delivery vectors. J Colloid Interface Sci 449:304-316. https://doi.org/10. 1016/j.jcis.2015.01.022

88. Spoeckner S, Wray V, Nimtz M, Lang S (1999) Glycolipids of the smut fungus Ustilago maydis from cultivation on renewable resources. Appl Microbiol Biotechnol 51:33-39. https://doi.org/ $10.1007 / \mathrm{s} 002530051359$

89. Deml G, Anke T, Oberwinkler F, Max Giannetti B, Steglich W (1980) Schizonellin A and B, new glycolipids from Schizonella melanogramma. Phytochemistry 19:83-87. https://doi.org/10. 1016/0031-9422(80)85018-7

90. Rau U, Nguyen LA, Roeper H, Koch H, Lang S (2005) Fed-batch bioreactor production of mannosylerythritol lipids secreted by Pseudozyma aphidis. Appl Microbiol Biotechnol 68:607-613. https://doi.org/10.1007/s00253-005-1906-5

91. Hewald S, Linne U, Scherer M, Marahiel MA, Kämper J, Bölker M (2006) Identification of a gene cluster for Biosynthesis of Mannosylerythritol lipids in the Basidiomycetous fungus Ustilago maydis. Appl Environ Microbiol 72:5469-5477. https://doi. org/10.1128/AEM.00506-06

92. Deinzer HT, Linne U, Xie X, Bölker M, Sandrock, (2019) Elucidation of substrate specificities of decorating enzymes involved in mannosylerythritol lipid production by cross-species complementation. Fungal Genet Biol 130:91-97. https://doi.org/10. 1016/j.fgb.2019.05.003

93. Saika A, Koike H, Fukuoka T, Morita T (2018) Tailor-made mannosylerythritol lipids: current state and perspectives. Appl Microbiol Biotechnol 102:6877-6884. https://doi.org/10.1007/ s00253-018-9160-9

94. Fukuoka T, Yanagihara T, Imura T, Morita T, Sakai H, Abe M et al (2011) Enzymatic synthesis of a novel glycolipid biosurfactant, mannosylerythritol lipid-D and its aqueous phase behavior. Carbohydr Res 346:266-271. https://doi.org/10.1016/j.carRe s2010.11.025

95. Konishi M, Makino M (2018) Selective production of deacetylated mannosylerythritol lipid, MEL-D, by acetyltransferase disruption mutant of Pseudozyma hubeiensis. J Biosci Bioeng 125:105-110. https://doi.org/10.1016/j.jbiosc.2017.08.003

96. Yoshida S, Koitabashi M, Nakamura J, Fukuoka T, Sakai H, Abe M et al (2015) Effects of biosurfactants, mannosylerythritol lipids, on the hydrophobicity of solid surfaces and infection behaviours of plant pathogenic fungi. J Appl Microbiol 119:215224. https://doi.org/10.1111/jam.12832

97. Arutchelvi JI, Bhaduri S, Uppara PV, Doble M (2008) Mannosylerythritol lipids: a review. J Ind Microbiol Biotechnol 35:15591570. https://doi.org/10.1007/s10295-008-0460-4

98. Wu J, Niu Y, Jiao Y, Chen Q (2019) Fungal chitosan from Agaricus bisporus (Lange) Sing. Chaidam increased the stability and antioxidant activity of liposomes modified with biosurfactants and loading betulinic acid. Int J Biol Macromol 123:291-299. https://doi.org/10.1016/j.ijbiomac.2018.11.062

99. Fan L, Li H, Niu Y, Chen Q (2016) Characterization and inducing Melanoma cell apoptosis activity of Mannosylerythritol lipids-a produced from Pseudozyma aphidis. PLoS ONE 11:e0148198. https://doi.org/10.1371/journalpone.0148198

100. Inoh Y, Kitamoto D, Hirashima N, Nakanishi M (2004) Biosurfactant MEL-A dramatically increases gene transfection via membrane fusion. J Control Release 94:423-431. https://doi.org/ 10.1016/j.jconrel.2003.10.020

101. Bakur A, Niu Y, Kuang H, Chen Q (2019) Synthesis of gold nanoparticles derived from mannosylerythritol lipid and evaluation of their bioactivities. AMB Express 9:1-9. https://doi.org/ 10.1186/s13568-019-0785-6

102. Kitamoto D, Isoda H, Nakahara T (2002) Functions and potential applications of glycolipid biosurfactant—from energy—saving materials to gene delivery carriers. J Biosci Bioeng 94:187-201. https://doi.org/10.1016/S1389-1723(02)80149-9

103. Nashida J, Nishi N, Takahashi Y, Hayashi C, Igarashi M, Takahashi D et al (2008) Systematic and stereoselective total synthesis of Mannosylerythritol lipids and evaluation of their antibacterial activity. J Org Chem 83:7281-7289. https://doi.org/10.1021/ acs.joc. 8 b00032

104. Piotrowski M, Lewandowska J, Wojciechowski K (2012) Biosurfactant-protein mixtures: Quillaja bark Saponin at water/air and water/oil interfaces in presence of $\beta$-Lactoglobulin. J Phys Chem B 116:4843-4850. https://doi.org/10.1021/jp301174d

105. Kitagawa M, Suzuki M, Yamamoto S, Sogabe (2008) Skin care cosmetic and skin and agent for preventing skin roughness containing biosurfactants. Eur Pat Specif - EP 1964546 B1. https:// data.epo.org/gpi/EP1964546A1

106. Takahashi M, Morita T, Fukuoka T, Imura T, Kitamoto D (2012) Glycolipid Biosurfactants, Mannosylerythritol lipids, show antioxidant and protective effects against $\mathrm{H} 2 \mathrm{O} 2$-induced oxidative stress in cultured human skin fibroblasts. J Oleo Sci 61:457-464. https://doi.org/10.5650/jos.61.457

107. dos Reis CBL, Morandini LMB, Bevilacqua CB, Bublitz F, Ugalde G, Mazutti MA et al (2018) First report of the production of a potent biosurfactant with $\alpha, \beta$-trehalose by Fusarium fujikuroi under optimized conditions of submerged fermentation. Brazilian J Microbiol 49:185-192. https://doi.org/10.1016/j.bjm. 2018.04.004

108. Morita T, Fukuoka T, Imura T, Kitamoto D (2016) Glycolipid biosurfactants In: reference module in chemistry, molecular sciences and Chemical engineering. Elsevier 1-7. https://doi.org/ 10.1016/B978-0-12-409547-2.11565-3

109. Franzetti A, Gandolfi I, Bestetti G, Smyth TJP, Banat IM (2010) Production and applications of trehalose lipid biosurfactants. Eur J Lipid Sci Technol 112(6):617-627. https://doi.org/10.1002/ejlt. 20090016

110. Hubert J, Plé K, Hamzaoui M, Nuissier G, Hadef I, Reynaud $R$ et al (2012) New perspectives for microbial glycolipid fractionation and purification processes. Comptes Rendus Chim 15(1):18-28. https://doi.org/10.1016/j.crci.2011.11.002

111. Joshi-Navare K, Singh PK, Prabhune AA (2014) New yeast isolate Pichia caribbica synthesizes xylolipid biosurfactant with enhanced functionality. Eur J Lipid Sci Technol 116:1070-1079. https://doi.org/10.1002/ejlt.201300363

112. Bölker M, Basse CW, Schirawski J (2008) Ustilago maydis secondary metabolism - from genomics to biochemistry. Fungal Genet Biol 45:S88-S93. https://doi.org/10.1016/j.fgb.2008.05. 007

113. Puchkov EO, Zähringer U, Lindner B, Kulakovskaya TV, Seydel U, Wiese A (2002) The mycocidal, membrane-active complex of Cryptococcus humicola is a new type of cellobiose lipid with detergent features. Biochim BioPhys Acta Biomembr 1558:161170. https://doi.org/10.1016/S0005-2736(01)00428-X

114. Kulakovskaya TV, Shashkov AS, Kulakovskaya EV, Golubev WI (2005) Ustilagic acid secretion by Pseudozyma fusiformata strains. FEMS Yeast Res 5:919-923. https://doi.org/10.1016/j. femsyr.2005.04.006

115. Morita T, Fukuoka T, Imura T, Kitamoto D (2013) Accumulation of cellobiose lipids under nitrogen-limiting conditions by two ustilaginomycetous yeasts, Pseudozyma aphidis and Pseudozyma hubeiensis. FEMS Yeast Res 13:44-49. https://doi.org/10.1111/ 1567-1364.12005

116. Cheng Y, McNally DJ, Labbé C, Voyer N, Belzile F, Bélanger RR (2003) Insertional mutagenesis of a fungal biocontrol agent led to discovery of a rare cellobiose lipid with antifungal activity. Appl Environ Microbiol 69:2595-2602. https://doi.org/10.1128/ AEM.69.5.2595-2602.2003 
117. Kulakovskaya TV, Shashkov AS, Kulakovskaya EV, Golubev WI (2004) Characterization of an antifungal glycolipid secreted by the yeast Sympodiomycopsis paphiopedili. FEMS Yeast Res 5:247-252. https://doi.org/10.1016/j.femsyr.2004.07.008

118. Kulakovskaya TV, Golubev WI, Tomashevskaya MA, Kulakovskaya EV, Shashkov AS, Grachev AA et al (2010) Production of antifungal cellobiose lipids by Trichosporon porosum. Mycopathologia 169:117-123. https://doi.org/10.1007/ s11046-009-9236-2

119. Imura T, Kawamura D, Ishibashi Y, Morita T, Sato S, Fukuoka $\mathrm{T}$ et al (2012) Low molecular weight gelators based on Biosurfactants, cellobiose lipids by Cryptococcus humicola. J Oleo Sci 61:659-664. https://doi.org/10.5650/jos.61.659

120. Imura $T$, Yamamoto $S$, Yamashita $C$, Taira $T$, Minamikawa $H$, Morita $\mathrm{T}$ et al (2014) Aqueous gel formation from sodium salts of cellobiose lipids. J Oleo Sci 63(10):1005-1010. https://doi. org/10.5650/jos.ess 14104

121. Fukuoka T, Morita T, Saika A, Habe H (2018) Application of glycolipid biosurfactants as surface modifiers in bioplastics. J Oleo Sci 67:1609-1616. https://doi.org/10.5650/jos.ess 18116

122. Garay LA, Sitepu IR, Cajka T, Fiehn O, Cathcart E, Fry RW et al (2017) Discovery of synthesis and secretion of polyol esters of fatty acids by four basidiomycetous yeast species in the order Sporidiobolales. J Ind Microbiol Biotechnol 44:923-936. https:// doi.org/10.1007/s10295-017-1919-y

123. Price NPJ, Manitchotpisit P, Vermillion KE, Bowman MJ, Leathers TD (2013) Structural characterization of novel extracellular liamocins (mannitol oils) produced by Aureobasidium pullulans strain NRRL 50380. Carbohydr Res 370:24-32. https://doi.org/ 10.1016/j.carRes2013.01.014

124. Cajka T, Garay LA, Sitepu IR, Boundy-Mills KL, Fiehn O (2016) Multiplatform mass spectrometry-based approach identifies extracellular glycolipids of the yeast Rhodotorula babjevae UCDFST 04-877. J Nat Prod 79:2580-2589. https://doi.org/10. 1021/acs.jnatProd6b00497

125. Saika A, Fukuoka T, Mikome S, Kondo Y, Habe H, Morita T (2020) Screening and isolation of the liamocin-producing yeast Aureobasidium melanogenum using xylose as the sole carbon source. J Biosci Bioeng 129(4):428-434. https://doi.org/10. 1016/j.jbiosc.2019.10.010

126. Lyman M, Rubinfeld B, Leif R, Mulcahy H, Dugan L, Souza B (2018) Rhodotorula taiwanensis MD1149 produces hypoacetylated PEFA compounds with increased surface activity compared to Rhodotorula babjevae MD1169. PLoS ONE 13:e0190373. https://doi.org/10.1371/journalpone.0190373

127. Price NPJ, Bischoff KM, Leathers TD, Cossé AA, Manitchotpisit P (2017) Polyols, not sugars, determine the structural diversity of anti-streptococcal liamocins produced by Aureobasidium pullulans strain NRRL 50380. J Antibiot 70:136-141. https://doi. org/10.1038/ja.2016.92

128. Leathers TD, Skory CD, Price NPJ, Nunnally MS (2018) Medium optimization for production of anti-streptococcal liamocins by Aureobasidium pullulans. Biocatal Agric Biotechnol 13:53-57. https://doi.org/10.1016/j.bcab.2017.11.008

129. Leathers TD, Rich JO, Bischoff KM, Skory CD, Nunnally MS (2019) Inhibition of Streptococcus mutans and S. sobrinus biofilms by liamocins from Aureobasidium pullulans. Biotechnol Rep 21:e00300. https://doi.org/10.1016/j.btre.2018.e00300

130. Bischoff KM, Brockmeier SL, Skory CD, Leathers TD, Price NPJ, Manitchotpisit P et al (2018) Susceptibility of Streptococcus suis to liamocins from Aureobasidium pullulans. Biocatal Agric Biotechnol 15:291-294. https://doi.org/10.1016/j.bcab. 2018.06.025

131. Wang M, Mao W, Wang X, Li F, Wang J, Chi Z et al (2019) Efficient simultaneous production of extracellular polyol esters of fatty acids and intracellular lipids from inulin by a deep-sea yeast Rhodotorula paludigena P4R5. Microb Cell Fact 18:149. https://doi.org/10.1186/s12934-019-1200-3

132. do MarquesSilvaAndrade daBrancoJúniorOkadaTakaki NSATALRFSJFKGMC (2019) Lipopeptide biosurfactant produced by Mucor circinelloides UCP/WFCC 0001 applied in the removal of crude oil and engine oil from soil. Acta Sci Technol 41:1-10. https://doi.org/10.4025/actascitechnol.v41i1.38986

133. Yu Z, Lang G, Kajahn I, Schmaljohann R, Imhoff JF (2008) Scopularides A and B, cyclodepsipeptides from a marine spongederived fungus, Scopulariopsis brevicaulis. J Nat Prod 71:10521054. https://doi.org/10.1021/np070580e

134. Sy-Cordero AA, Pearce CJ, Oberlies NH (2012) Revisiting the enniatins: a review of their isolation, biosynthesis, structure determination and biological activities. J Antibiot 65:541-549. https://doi.org/10.1038/ja.2012.71

135. Rufino RD, de Luna JM, de Campos Takaki GM, Sarubbo LA (2014) Characterization and properties of the biosurfactant produced by Candida lipolytica UCP 0988. Electron J Biotechnol 17:34-38. https://doi.org/10.1016/j.ejbt.2013.12.006

136. Santos DKF, Meira HM, Rufino RD, Luna JM, Sarubbo LA (2017) Biosurfactant production from Candida lipolytica in bioreactor and evaluation of its toxicity for application as a bioremediation agent. Process BioChem 54:20-27. https://doi.org/10. 1016/j.procbio.2016.12.020

137. Dokouhaki M, Hung A, Kasapis S, Gras SL (2021) Hydrophobins and chaplins: novel bio-surfactants for food dispersions a review. Trends Food Sci Technol 111:378-387. https://doi.org/ 10.1016/j.tifs.2021.03.001

138. Kulkarni S, Nene S, Joshi K (2017) Production of Hydrophobins from fungi. Process Biochem 61:1-11. https://doi.org/10.1016/j. procbio.2017.06.012

139. Linder MB (2009) Hydrophobins: proteins that self assemble at interfaces. Curr Opin Colloid Interface Sci 14:356-363. https:// doi.org/10.1016/j.cocis.2009.04.001

140. Berger BW, Sallada ND (2019) Hydrophobins: multifunctional biosurfactants for interface engineering. J Biol Eng 13:1-8. https://doi.org/10.1186/s13036-018-0136-1

141. Vigueras G, Shirai K, Hernández-Guerrero M, Morales M, Revah S (2014) Growth of the fungus Paecilomyces lilacinus with n-hexadecane in submerged and solid-state cultures and recovery of hydrophobin proteins. Process BioChem 49:1606-1611. https://doi.org/10.1016/j.procbio.2014.06.015

142. Aimanianda V, Bayry J, Bozza S, Kniemeyer O, Perruccio K, Elluru SR et al (2009) Surface hydrophobin prevents immune recognition of airborne fungal spores. Nature 460:1117-1121. https://doi.org/10.1038/nature08264

143. Van Hamme JD, Singh A, Ward OP (2006) Physiological aspects Part 1 in a series of papers devoted to surfactants in microbiology and biotechnology. Biotechnol Adv 24:604-620. https://doi.org/ 10.1016/j.biotechadv.2006.08.001

144. Cameotra SS, Makkar RS, Kaur J, Mehta SK (2010) Synthesis of biosurfactants and their advantages to microorganisms and mankind In: advances in experimental medicine and biology. 261-280. https://doi.org/10.1007/978-1-4419-5979-9_20

145. Van Bogaert INA, Saerens K, De Muynck C, Develter D, Soetaert W, Vandamme EJ (2007) Microbial production and application of sophorolipids. Appl Microbiol Biotechnol 76:23-34. https://doi.org/10.1007/s00253-007-0988-7

146. Mimee B, Labbe C, Belanger RR (2009) Catabolism of flocculosin, an antimicrobial metabolite produced by Pseudozyma flocculosa. Glycobiology 19:995-1001. https://doi.org/10.1093/ glycob/cwp078

147. Silva MET, Duvoisin S, Oliveira RL, Banhos EF, Souza AQL, Albuquerque PM (2019) Biosurfactant production of Piper hispidum endophytic fungi. J Appl Microbiol 2022:1-9. https://doi. org/10.1111/jam.14398 
148. Selbmann L, Onofri S, Fenice M, Federici F, Petruccioli M (2002) Production and structural characterization of the exopolysaccharide of the Antarctic fungus Phoma herbarum CCFEE 5080. Res Microbiol 153:585-592. https://doi.org/10.1016/ S0923-2508(02)01372-4

149. da Araújo SC, S, Silva-Portela RCB, de Lima DC, da Fonsêca MMB, Araújo WJ, da Silva UB, et al (2020) MBSP1: a biosurfactant protein derived from a metagenomic library with activity in oil degradation. Sci Rep 10:1-13. https://doi.org/10.1038/ s41598-020-58330-x 1

150. Kim JS, Lee IK, Yun BS (2015) A novel Biosurfactant produced by Aureobasidium pullulans L3-GPY from a tiger lily wild flower Lilium lancifoliumThunb. PLoS ONE 10:e0122917. https://doi. org/10.1371/journalpone.0122917

151. Yalçın HT, Ergin-Tepebaşı G, Uyar E (2018) Isolation and molecular characterization of biosurfactant producing yeasts from the soil samples contaminated with petroleum derivatives. J Basic Microbiol 58:782-792. https://doi.org/10.1002/jobm. 201800126

152. Adnan M, Alshammari E, Ashraf SA, Patel K, Lad K, Patel M (2018) Physiological and molecular characterization of Biosurfactant producing Endophytic Fungi Xylaria regalis from the Cones of Thuja plicata as a potent plant growth promoter with its potential application. Biomed Res Int 2018:1-11. https://doi. org/10.1155/2018/7362148

153. Derguine-Mecheri L, Kebbouche-gana S, Khemili-talbi S, Djenane D (2018) Screening and biosurfactant/bioemulsifier production from a high-salt-tolerant halophilic Cryptococcus strain YLF isolated from crude oil. J Pet Sci Eng 162:712-724. https://doi.org/10.1016/j.petrol.2017.10.088

154. Mousavi F, Beheshti-Maal K, Massah A (2015) Production of Sophorolipid from an Identified Current Yeast, Lachancea thermotolerans BBMCZ7FA20, Isolated from Honey Bee. Curr Microbiol 71:303-310. https://doi.org/10.1007/ s00284-015-0841-7

155. Bueno JL, Santos PAD, da Silva RR, Moguel IS, Pessoa A, Vianna MV et al (2019) Biosurfactant production by yeasts from different types of soil of the South Shetland Islands (Maritime Antarctica). J Appl Microbiol 126:1402-1413. https://doi.org/ 10.1111/jam.14206

156. Jackson SA, Borchert E, O'Gara F, Dobson AD (2015) Metagenomics for the discovery of novel biosurfactants of environmental interest from marine ecosystems. Curr Opin Biotechnol 33:176182. https://doi.org/10.1016/j.copbio.2015.03.004

157. Williams W, Trindade M (2017) Metagenomics for the discovery of novel biosurfactants. functional metagenomics: tools and applications. Springer International Publishing, Cham, pp 95-117. https://doi.org/10.1007/978-3-319-61510-3_6

158. Kodzius R, Gojobori T (2015) Marine metagenomics as a source for bioprospecting. Mar Genomics 24:21-30. https://doi.org/10. 1016/j.margen2015.07.001

159. Thies S, Rausch SC, Kovacic F, Schmidt-Thaler A, Wilhelm S, Rosenau F et al (2016) Metagenomic discovery of novel enzymes and biosurfactants in a slaughterhouse biofilm microbial community. Sci Rep 6:27035. https://doi.org/10.1038/srep27035

160. Schultz J, Rosado AS (2020) Extreme environments: a source of biosurfactants for biotechnological applications. Extremophiles 24(2):189-206. https://doi.org/10.1007/s00792-019-01151-2

161. Trudgeon B, Dieser M, Balasubramanian N, Messmer M, Foreman CM (2020) Low-temperature biosurfactants from polar microbe. Microorganisms. https://doi.org/10.3390/microorgan isms 8081183

162. Hughes KA, Bridge P, Clark MS (2007) Tolerance of Antarctic soil fungi to hydrocarbons. Sci Total Environ 372:539-548. https://doi.org/10.1016/j.scitotenv.2006.09.016
163. Baldeweg F, Warncke P, Fischer D, Gressler M (2019) Fungal biosurfactants from Mortierella alpina. Org Lett 21:1444-1448. https://doi.org/10.1021/acs.orglett.9b00193

164. Perfumo A, Banat IM, Marchant R (2018) Going green and cold: biosurfactants from low-temperature environments to biotechnology applications. Trends Biotechnol 36:277-289. https://doi.org/ 10.1016/j.tibtech.2017.10.016

165. Kitamoto D, Yanagishita H, Endo A, Nakaiwa M, Nakane T, Akiya T (2001) Remarkable antiagglomeration effect of a yeast biosurfactant, Diacylmannosylerythritol, on ice-water Slurry for cold thermal storage. Biotechnol Prog 17:362-365. https://doi. org/10.1021/bp000159f

166. Correa HT, Vieira WF, Pinheiro TMA, Cardoso VL, Silveira E, Sette LD et al (2020) L-asparaginase and biosurfactants produced by extremophile yeasts from Antarctic environments. Ind Biotechnol 16:107-116. https://doi.org/10.1089/Ind2019.0037

167. Chen G-Q, Jiang X-R (2018) Next generation industrial biotechnology based on extremophilic bacteria. Curr Opin Biotechnol 50:94-100. https://doi.org/10.1016/j.copbio.2017.11.016

168. Twigg MS, Baccile N, Banat IM, Déziel E, Marchant R, Roelants S et al (2020) Microbial biosurfactant research: time to improve the rigour in the reporting of synthesis, functional characterization and process development. Microb Biotechnol 14:147-170. https://doi.org/10.1111/1751-7915.13704

169. Kiran GS, Thomas TA, Selvin J (2010) Production of a new glycolipid biosurfactant from marine Nocardiopsis lucentensis MSA04 in solid-state cultivation. Coll Surf B Biointerfaces 78:8-16. https://doi.org/10.1016/j.colsurfb.2010.01.028

170. Ojha N, Mandal SK, Das N (2019) Enhanced degradation of indeno(1,2,3-cd)pyrene using Candida tropicalis NN4 in presence of iron nanoparticles and produced biosurfactant: a statistical approach. Biotech 9:86. https://doi.org/10.1007/ s13205-019-1623-x

171. Onwosi CO, Aliyu GO, Onu CJ, Chukwu KO, Ndukwe JK, Igbokwe VC (2021) Microbial-derived glycolipids in the sustainable formulation of biomedical and personal care products $\mathrm{A}$ consideration of the process economics towards commercialization. Process BioChem 100:124-139. https://doi.org/10.1016/j. procbio.2020.10.001

172. Mercadé ME, Monleón L, de Andrés C, Rodón I, Martinez E, Espuny MJ et al (1996) Screening and selection of surfactantproducing bacteria from waste lubricating oil. J Appl Bacteriol 81:161-166. https://doi.org/10.1111/j.1365-2672.1996.tb04494.x

173. Zadeh PH, Moghimi H, Hamedi J (2018) Biosurfactant production by Mucor circinelloides: environmental applications and surface-active properties. Eng Life Sci 18:317-325. https://doi. org/10.1002/elsc.201700149

174. du Noüy PL (1925) An interfacial tensiometer for universal use. J Gen Physiol 7:625-631. https://doi.org/10.1085/jgp.7.5.625

175. Ebnesajjad S (2011) Surface tension and its measurement In: handbook of adhesives and surface preparation. Elsevier 21-30. https://doi.org/10.1016/B978-1-4377-4461-3.10003-3

176. Bodour AA, Miller-Maier RM (1988) Methods application of a modified drop-collapse technique for surfactant quantitation and screening of biosurfactant-producing microorganisms. J Microbiol Methods 32:273-280. https://doi.org/10.1016/S01677012(98)00031-1

177. Ong SA, Wu JC (2018) A simple method for rapid screening of biosurfactant-producing strains using bromothymol blue alone. Biocatal Agric Biotechnol 16:121-125. https://doi.org/10.1016/j. bcab.2018.07.027

178. Youssef NH, Duncan KE, Nagle DP, Savage KN, Knapp RM, McInerney MJ (2004) Comparison of methods to detect biosurfactant production by diverse microorganisms. J Microbiol Methods 56:339-347. https://doi.org/10.1016/Jmimet.2003.11. 001 
179. Jain DK, Collins-Thompson DL, Lee H, Trevors JT (1991) A drop-collapsing test for screening surfactant-producing microorganisms. J Microbiol Methods 13:271-279. https://doi.org/10. 1016/0167-7012(91)90064-W

180. Mohanram R, Jagtap C, Kumar, (2016) Isolation, screening, and characterization of surface-active agent-producing, oil-degrading marine bacteria of Mumbai Harbor. Mar Pollut Bull 105:131138. https://doi.org/10.1016/j.marpolbul.2016.02.040

181. Woźniak-Karczewska M, Myszka K, Sznajdrowska A, Szulc A, Zgoła-Grześkowiak A, Ławniczak $€$ et al (2017) Isolation of rhamnolipids-producing cultures from faeces: Influence of interspecies communication on the yield of rhamnolipid congeners. $\mathrm{N}$ Biotechnol 36:17-25. https://doi.org/10.1016/j.nbt.2016.12.008

182. Kuiper I, Lagendijk EL, Pickford R, Derrick JP, Lamers GEM, Thomas-Oates JE et al (2003) Characterization of two Pseudomonas putida lipopeptide biosurfactants, putisolvin I and II, which inhibit biofilm formation and break down existing biofilms. Mol Microbiol 51:97-113. https://doi.org/10.1046/j.13652958.2003.03751.x

183. Qiao N, Shao Z (2010) Isolation and characterization of a novel biosurfactant produced by hydrocarbon-degrading bacterium Alcanivorax dieselolei B-5. J Appl Microbiol 108:1207-1216. https://doi.org/10.1111/j.1365-2672.2009.04513.x

184. Archana K, Sathi Reddy K, Parameshwar J, Bee H (2019) Isolation and characterization of sophorolipid producing yeast from fruit waste for application as antibacterial agent. Environ Sustain 2:107-115. https://doi.org/10.1007/s42398-019-00069-x

185. Yela ACA, Martínez MAT, Piñeros GAR, López VC, Villamizar SH, Vélez VLN et al (2016) A comparison between conventional Pseudomonas aeruginosa rhamnolipids and Escherichia coli transmembrane proteins for oil recovery enhancing. Int Biodeterior Biodegrad 112:59-65. https://doi.org/10.1016/j.ibiod. 2016.04.033

186. Silva NRA, Luna MAC, Santiago ALCMA, Franco LO, Silva GKB, de Souza PM et al (2014) Biosurfactant-and-bioemulsifier produced by a promising Cunninghamella echinulata isolated from caatinga soil in the Northeast of Brazil. Int J Mol Sci 15:15377-15395. https://doi.org/10.3390/ijms 150915377

187. Cooper DG, Goldenberg BG (1987) Surface-active agents from two bacilllus species. Appl Environ Microbiol 53:224-229. https://doi.org/10.1128/AEM.53.2.224-229.1987

188. Shah MUH, Sivapragasam M, Moniruzzaman M, Talukder MMR, Yusup SB, Goto M (2017) Production of sophorolipids by Starmerella bombicola yeast using new hydrophobic substrates. BioChem Eng J 127:60-67. https://doi.org/10.1016/j.bej.2017. 08.005

189. Velioglu Z, Urek RO (2016) Physicochemical and structural characterization of biosurfactant produced by Pleurotus djamor in solid-state fermentation. Biotechnol Bioprocess Eng 21:430-438. https://doi.org/10.1007/s12257-016-0139-Z

190. Haba E, Espuny MJ, Busquets M, Manresa A (2000) Screening and production of rhamnolipids by Pseudomonas aeruginosa 47T2 NCIB 40044 from waste frying oils. J Appl Microbiol 88:379-387. https://doi.org/10.1046/j.1365-2672.2000.00961.x

191. Satpute SK, Banpurkar AG, Dhakephalkar PK, Banat IM, Chopade BA (2010) Methods for investigating biosurfactants and bioemulsifiers: a review. Crit Rev Biotechnol 30:127-144. https://doi.org/10.3109/07388550903427280

192. Pele MA, Ribeaux DR, Vieira ER, Souza AF, Luna MAC, Rodríguez DM et al (2019) Conversion of renewable substrates for biosurfactant production by Rhizopus arrhizus UCP 1607 and enhancing the removal of diesel oil from marine soil. Electron $\mathbf{J}$ Biotechnol 38:40-48. https://doi.org/10.1016/j.ejbt.2018.12.003

193. Desai JD, Banat IM (1997) Microbial production of surfactants and their commercial potential. Microbiol Mol Biol Rev 61:47-64
194. Sánchez-Vázquez V, Shirai K, González I, Gutiérrez-Rojas M (2018) Polycyclic aromatic hydrocarbon-emulsifier protein produced by Aspergillus brasiliensis (niger) in an airlift bioreactor following an electrochemical pretreatment. Bioresour Technol 256:408-413. https://doi.org/10.1016/j.biortech.2018.02.043

195. Varjani SJ, Upasani VN (2017) Critical review on biosurfactant analysis, purification and characterization using rhamnolipid as a model biosurfactant. Bioresour Technol 232:389-397. https:// doi.org/10.1016/j.biortech.2017.02.047

196. Rosenberg M, Gutnick D, Rosenberg E (1980) Adherence of bacteria to hydrocarbons: a simple method for measuring cellsurface hydrophobicity. FEMS Microbiol Lett 9:29-33. https:// doi.org/10.1111/j.1574-6968.1980.tb05599.x

197. EL-HanafyAnwarSabirMohamedAl-GarniZinadah AAEMYJSMSASMSOAHA et al (2017) Characterization of native fungi responsible for degrading crude oil from the coastal area of Yanbu Saudi Arabia. Biotechnol Biotechnol Equip 31:105-111. https://doi.org/10.1080/13102818.2016.1249407

198. Al-Hawash AB, Zhang J, Li S, Liu J, Ghalib HB, Zhang X et al (2018) Biodegradation of n-hexadecane by Aspergillus sp. RFC-1 and its mechanism. Ecotoxicol Environ Saf 164:398-408. https://doi.org/10.1016/j.ecoenv.2018.08.049

199. Kaur K, Sangwan S, Kaur H (2017) Biosurfactant production by yeasts isolated from hydrocarbon polluted environments. Environ Monit Assess 189:603. https://doi.org/10.1007/ s10661-017-6311-x

200. Al-Hawash AB, Zhang X, Ma F (2019) Removal and biodegradation of different petroleum hydrocarbons using the filamentous fungus Aspergillus sp. RFC-1. Microbiol Open 8:e00619. https:// doi.org/10.1002/mbo3.619

201. Smits THM, Wick LY, Harms H, Keel C (2003) Characterization of the surface hydrophobicity of filamentous fungi. Environ Microbiol 5:85-91. https://doi.org/10.1046/j.1462-2920.2003. 00389.x

202. Wai H, Cheng B, Kheng Y, Vujanovic V (2009) A novel method for identifying hydrophobicity on fungal surfaces. Mycol Res 113:1046-1052. https://doi.org/10.1016/j.mycRes2009.06.007

203. Siegmund I, Wagner F (1991) New method for detecting rhamnolipids excreted byPseudomonas species during growth on mineral agar. Biotechnol Tech 5:265-268. https://doi.org/10.1007/ BF02438660

204. Mnif I, Ghribi D (2015) Microbial derived surface active compounds: properties and screening concept. World J Microbiol Biotechnol 31:1001-1020. https://doi.org/10.1007/ s11274-015-1866-6

205. Spina F, Spini G, Poli A, Romagnolo A, Zanellati A, Bentivegna NG et al (2018) Screening of anionic biosurfactants production among fungi and bacteria. Chem Eng Trans 64:493-498. https:// doi.org/10.3303/CET1864083

206. Kabbout R, Taha S (2014) Biodecolorization of textile dye effluent by biosorption on fungal biomass materials. Phys Procedia 55:437-444. https://doi.org/10.1016/j.phpro.2014.07.063

207. Mulligan CN, Cooper DG (1984) Selection of microbes producing biosurfactants in media without hydrocarbons. J Ferment Technol 62:311-314

208. Ferreira INS, Rodríguez DM, Campos-Takaki GM, da Andrade RF, S, (2020) Biosurfactant and bioemulsifier as promising molecules produced by Mucor hiemalis isolated from Caatinga soil. Electron J Biotechnol 47:51-58. https://doi.org/10.1016/j.ejbt. 2020.06.006

209. Marcelino PRF, Peres GFD, Terán-hilares R, Pagnocca FC, Rosa CA, Lacerda TM et al (2019) Biosurfactants production by yeasts using sugarcane bagasse hemicellulosic hydrolysate as new sustainable alternative for lignocellulosic biorefineries. Ind Crop Prod 129:212-223. https://doi.org/10.1016/j.indcrop.2018.12. 001 
210. Dehghan-Noudeh G, Housaindokht M, Bazzaz BSF (2005) Isolation, characterization, and investigation of surface and hemolytic activities of a lipopeptide biosurfactant produced by ATCC 6633 . J Microbiol 43:272-276

211. Rizzo C, Rappazzo AC, Michaud L, De Domenico E, Rochera C, Camacho A et al (2018) Efficiency in hydrocarbon degradation and biosurfactant production by Joostella sp. A8 when grown in pure culture and consortia. J Environ Sci 67:115-126. https://doi. org/10.1016/j.jes.2017.08.007

212. Chen C, Baker SC, Darton RC (2007) The application of a high throughput analysis method for the screening of potential biosurfactants from natural sources. J Microbiol Methods 70:503-510. https://doi.org/10.1016/j.mimet.2007.06.006

213. Zaky AS, Tucker GA, Daw ZY, Du C (2014) Marine yeast isolation and industrial application. FEMS Yeast Res 14:813-825. https://doi.org/10.1111/1567-1364.12158

214. Balan SS, Ganesh Kumar C, Jayalakshmi S (2019) Physicochemical, structural and biological evaluation of Cybersan (trigalactomargarate), a new glycolipid biosurfactant produced by a marine yeast, Cyberlindnera saturnus strain SBPN-27. Process BioChem 80:171-180. https://doi.org/10.1016/j.procbio.2019.02.005

215. Morita T, Konishi M, Fukuoka T, Imura T, Kitamoto D (2007) Physiological differences in the formation of the glycolipid biosurfactants, mannosylerythritol lipids, between Pseudozyma antarctica and Pseudozyma aphidis. Appl Microbiol Biotechnol 74:307-315. https://doi.org/10.1007/s00253-006-0672-3

216. Colla ML, Rizzardi J, Pinto M, Reinehr C, Bertolin ET, Costa JAV (2010) Simultaneous production of lipases and biosurfactants by submerged and solid-state bioprocesses. Bioresour Technol 101:8308-8314. https://doi.org/10.1016/j.biortech.2010. 05.086

217. Adamczak M, Bednarski W (2000) Influence of medium composition and aeration on the synthesis of biosurfactants produced by Candida antarctica. Biotechnol Lett 22:313-316. https://doi. org/10.1023/A:1005634802997

218. Kulkarni SS, Nene SN, Joshi KS (2020) A comparative study of production of hydrophobin like proteins (HYD-LPs) in submerged liquid and solid state fermentation from white rot fungus Pleurotus ostreatus. Biocatal Agric Biotechnol 23:101440. https://doi.org/10.1016/j.bcab.2019.101440

219. Krieger N, Neto DC, Mitchell DA (2010) Production of microbial biosurfactants by solid-state cultivation. Biosurfactants 2010:203-210. https://doi.org/10.1007/978-1-4419-5979-9_15

220. Jiménez-Peñalver P, Gea T, Sánchez A, Font X (2016) Production of sophorolipids from winterization oil cake by solid-state fermentation: optimization, monitoring and effect of mixing. BioChem Eng J 115:93-100. https://doi.org/10.1016/j.bej.2016. 08.006

221. Singh P, Patil Y, Rale V (2019) Biosurfactant production: emerging trends and promising strategies. J Appl Microbiol 126:2-13. https://doi.org/10.1111/jam.14057

222. Banat IM, Satpute SK, Cameotra SS, Patil R, Nyayanit NV (2014) Cost effective technologies and renewable substrates for biosurfactants' production. Front Microbiol 5:1-18. https://doi. org/10.3389/fmicb.2014.00697

223. Garay LA, Sitepu IR, Cajka T, Cathcart E, Fiehn O, German JB et al (2017) Simultaneous production of intracellular triacylglycerols and extracellular polyol esters of fatty acids by Rhodotorula babjevae and Rhodotorula aff paludigena. J Ind Microbiol Biotechnol 44:1397-1413. https://doi.org/10.1007/ s10295-017-1964-6

224. Martinho V, dos Santos Lima LM, Barros CA, Ferrari VB, Passarini MRZ, Santos LA et al (2019) Enzymatic potential and biosurfactant production by endophytic fungi from mangrove forest in Southeastern Brazil. AMB Express 9:130. https://doi. org/10.1186/s13568-019-0850-1
225. Kreling NE, Simon V, Fagundes VD, Thomé A, Colla LM (2020) Simultaneous production of lipases and biosurfactants in solidstate fermentation and use in bioremediation. J Environ Eng 146:04020105. https://doi.org/10.1061/(ASCE)EE.1943-7870. 0001785

226. Velioglu Z, Urek RO (2014) Concurrent biosurfactant and ligninolytic enzyme production by Pleurotus spp solid-state fermentation. Appl Biochem Biotechnol 74(4):1354-1364. https://doi.org/ 10.1007/s12010-014-1136-3

227. Faria NT, Marques S, Fonseca C, Ferreira FC (2015) Direct xylan conversion into glycolipid biosurfactants, mannosylerythritol lipids, by Pseudozyma antarctica PYCC 5048T. Enzyme Microb Technol 71:58-65. https://doi.org/10.1016/j.enzmictec.2014.10. 008

228. Jimoh AA, Senbadejo TY, Adeleke R, Lin J (2021) Development and genetic engineering of hyper-producing microbial strains for improved synthesis of biosurfactants. Mol Biotechnol 63(4):267288. https://doi.org/10.1007/s12033-021-00302-1

229. Souza KST, Gudiña EJ, Schwan RF, Rodrigues LR, Dias DR, Teixeira JA (2018) Improvement of biosurfactant production by Wickerhamomyces anomalus CCMA 0358 and its potential application in bioremediation. J Hazard Mater 346:152-158. https://doi.org/10.1016/j.jhazmat.2017.12.021

230. Yu X, Li X, Jin T, Su Y, Li J, Gao M et al (2021) Integrated biorefinery process for production of sophorolipids from corn straw. BioChem Eng J 167:107908. https://doi.org/10.1016/j.bej. 2020.107908

231. Brumano LP, Antunes FAF, Souto SG, dos Santos JC, Venus J, Schneider R et al (2017) Biosurfactant production by Aureobasidium pullulans in stirred tank bioreactor: new approach to understand the influence of important variables in the process. Bioresour Technol 243:264-272. https://doi.org/10.1016/j.biort ech.2017.06.088

232. Almeida DG, de Soares da Silva RCF, Luna JM, Rufino RD, Santos VA, Sarubbo LA (2017) Response surface methodology for optimizing the production of biosurfactant by Candida tropicalis on industrial waste substrates. Front Microbiol 8:1-13. https:// doi.org/10.3389/fmicb.2017.00157

233. Solaiman DKY, Ashby RD, Nuñez A, Foglia TA (2004) Production of sophorolipids by Candida bombicola grown on soy molasses as substrate. Biotechnol Lett 26:1241-1245. https:// doi.org/10.1023/B:BILE.0000036605.80577.30

234. da Silva JF, da Silva LAR, Barbosa MR, Houllou LM, Malafaia CB (2020) Bioemulsifier produced by Yarrowia lipolytica using residual glycerol as a carbon source. J Environ Anal Prog 5:31-37. https://doi.org/10.24221/jeap.5.1.2020.2700.031-037

235. Kaur G, Wang H, To MH, Roelants SLKW, Soetaert W, Lin CSK (2019) Efficient sophorolipids production using food waste. J Clean Prod 232:1-11. https://doi.org/10.1016/j.jclepro.2019.05. 326

236. Maddikeri GL, Gogate PR, Pandit AB (2015) Improved synthesis of sophorolipids from waste cooking oil using fed batch approach in the presence of ultrasound. Chem Eng J 263:479-487. https:// doi.org/10.1016/j.cej.2014.11.010

237. Souza KST, Gudiña EJ, Azevedo Z, de Freitas V, Schwan RF, Rodrigues LR et al (2017) New glycolipid biosurfactants produced by the yeast strain Wickerhamomyces anomalus CCMA 0358. Coll Surf B Biointerfaces 154:373-382. https://doi.org/10. 1016/j.colsurfb.2017.03.041

238. Santos DKF, Brandão YB, Rufino RD, Luna JM, Salgueiro AA, Santos VA et al (2014) Optimization of cultural conditions for biosurfactant production from Candida lipolytica. Biocatal Agric Biotechnol 3:48-57. https://doi.org/10.1016/j.bcab.2014.02.004

239. Kim J-H, Oh Y-R, Hwang J, Jang Y-A, Lee SS, Hong SH et al (2020) Value-added conversion of biodiesel into the versatile 
biosurfactant sophorolipid using Starmerella bombicola. Clean Eng Technol 1:100027. https://doi.org/10.1016/j.clet.2020. 100027

240. Delbeke EIP, Everaert J, Uitterhaegen E, Verweire S, Verlee A, Talou $\mathrm{T}$ et al (2016) Petroselinic acid purification and its use for the fermentation of new sophorolipids. AMB Express 6:1-9. https://doi.org/10.1186/s13568-016-0199-7

241. Maeng Y, Kim KT, Zhou X, Jin L, Kim KS, Kim YH et al (2018) A novel microbial technique for producing high-quality sophorolipids from horse oil suitable for cosmetic applications. Microb Biotechnol 11:917-929. https://doi.org/10.1111/17517915.13297

242. Bajaj VK, Annapure US (2015) Castor oil as secondary Carbon source for production of Sophorolipids using starmerella Bombicola NRRLY-17069. J Oleo Sci 64:315-323. https://doi.org/ 10.5650/jos.ess 14214

243. Wadekar SD, Kale SB, Lali AM, Bhowmick DN, Pratap AP (2012) Jatropha oil and karanja oil as carbon sources for production of sophorolipids. Eur J Lipid Sci Technol 114:823-832. https://doi.org/10.1002/ejlt.201100282

244. Santos MV, Faria NT, Fonseca C, Ferreira FC (2018) Production of mannosylerythritol lipids from lignocellulose hydrolysates:tolerance thresholds of Moesziomyces antarcticus to inhibitors. J Chem Technol Biotechnol 94:1064-1072. https:// doi.org/10.1002/jctb.5853

245. Castiglioni GL, Stanescu G, Rocha LAO, Costa JAV (2014) Analytical modeling and numerical optimization of the biosurfactants production in solid-state fermentation by Aspergillus fumigatus. Acta Sci Technol 36:61-67. https://doi.org/10.4025/actasciTec hnolv36i1.17818

246. Parekh VJ, Pandit AB (2012) Solid state fermentation (SSF) for the production of sophorolipids from Starmerella bombicola NRRL Y-17069 using glucose, wheat bran and oleic acid. Curr Trends Biotechnol Pharm. 6:418-424

247. Velioglu Z, Urek RO (2015) Optimization of cultural conditions for biosurfactant production by Pleurotus djamor in solid state fermentation. J Biosci Bioeng 120:526-531. https://doi.org/10. 1016/j.jbiosc.2015.03.007

248. Jiménez-Peñalver P, Castillejos M, Koh A, Gross R, Sánchez A, Font X et al (2018) Production and characterization of sophorolipids from stearic acid by solid-state fermentation, a cleaner alternative to chemical surfactants. J Clean Prod 172:2735-2747. https://doi.org/10.1016/j.jclepro.2017.11.138

249. Cerda A, Mejias L, Rodríguez P, Rodríguez A, Artola A, Font $X$ et al (2019) Valorisation of digestate from biowaste through solid-state fermentation to obtain value added bioproducts: a first approach. Bioresour Technol 271:409-416. https://doi.org/ 10.1016/j.biortech.2018.09.131

250. Liu Z, Tian X, Chen Y, Lin Y, Mohsin A, Chu J (2019) Efficient sophorolipids production via a novel in situ separation technology by Starmerella bombicola. Process BioChem 81:1-10. https://doi.org/10.1016/j.procbio.2018.12.005

251. Souza PM, Silva NRA, Souza DG, Silva TAL, Freitas-Silva MC, Andrade RFS et al (2018) Production of a biosurfactant by Cunninghamella echinulata using renewable substrates and Its applications in enhanced oil spill recovery. Coll Interfaces 2:63. https://doi.org/10.3390/colloids2040063

252. Saur KM, Brumhard O, Scholz K, Hayen H, Tiso T (2019) A pH shift induces high-titer liamocin production in Aureobasidium pullulans. Appl Microbiol Biotechnol 103:4741-4752. https:// doi.org/10.1007/s11682-018-9832-1

253. Ma XJ, Li H, Shao LJ, Shen J, Song X (2011) Effects of nitrogen sources on production and composition of sophorolipids by Wickerhamiella domercqiae var. sophorolipid CGMCC 1576. Appl Microbiol Biotechnol 91:1623-1632. https://doi.org/10. 1007/s00253-011-3327-y
254. Andrade RFS, Silva TAL, Ribeaux DR, Rodriguez DM, Souza AF, Lima MAB et al (2018) Promising Biosurfactant produced by Cunninghamella echinulata UCP 1299 using renewable resources and its application in cotton fabric cleaning process. Adv Mater Sci Eng 2018:1-12. https://doi.org/10.1155/2018/ 1624573

255. Chen J, Zhang H, Liu Y, Fu S, Liu X (2014) Metal ions can affect the composition and production of sophorolipids by Wickerhamiella domercqiae Y2A CGMCC 3798. Eur J Lipid Sci Technol 116:1505-1512. https://doi.org/10.1002/ejlt.201300512

256. Jiang J, Zu Y, Li X, Meng Q, Long X (2020) Recent progress towards industrial rhamnolipids fermentation: process optimization and foam control. Bioresour Technol 298:122394. https:// doi.org/10.1016/j.biortech.2019.122394

257. Zhang Y, Jia D, Sun W, Yang X, Zhang C, Zhao F et al (2018) Semicontinuous sophorolipid fermentation using a novel bioreactor with dual ventilation pipes and dual sieve-plates coupled with a novel separation system. Microb Biotechnol 11:455-464. https://doi.org/10.1111/1751-7915.13028

258. Van Dien S (2013) From the first drop to the first truckload: commercialization of microbial processes for renewable chemicals. Curr Opin Biotechnol 24:1061-1068. https://doi.org/10.1016/j. copbio.2013.03.002

259. Ochoa S (2019) Fed-batch fermentation -design strategies In: comprehensive biotechnology. Elsevier 586-600. https://doi.org/ 10.1016/B978-0-444-64046-8.00093-8J

260. Stanbury PF, Whitaker A, Hall SJ (2017) Culture preservation and inoculum development In: rinciples of fermentation technology. Elsevier 335-399. https://doi.org/10.1016/B978-0-08099953-1.00006-5

261. Posch AE, Herwig C, Spadiut O (2013) Science-based bioprocess design for filamentous fungi. Trends Biotechnol 31:37-44. https://doi.org/10.1016/j.tibtech.2012.10.008

262. Hall SM (2018) Bioprocessing, In: SM Hall (Eds) Rules of thumb for chemical engineers, Elsevier, pp 331-344. https://doi. org/10.1016/C2016-0-00182

263. Marti ME, Colonna WJ, Patra P, Zhang H, Green C, Reznik G et al (2014) Production and characterization of microbial biosurfactants for potential use in oil-spill remediation. Enzyme Microb Technol 55:31-39. https://doi.org/10.1016/j.enzmictec.2013.12. 001

264. Antony J (2014) Screening designs In: design of experiments for engineers and scientists. Elsevier 51-62. https://doi.org/10.1016/ B978-0-08-099417-8.00005-5

265. Stanbury PF, Whitaker A, Hall SJ (2017) Media for industrial fermentations In: principles of fermentation technology. Elsevier 213-272. https://doi.org/10.1016/B978-0-08-099953-1.00004-1

266. Meneses DP, Gudiña EJ, Fernandes F, Gonçalves LRB, Rodrigues LR, Rodrigues S (2017) The yeast-like fungus Aureobasidium thailandense LB01 produces a new biosurfactant using olive oil mill wastewater as an inducer. Microbiol Res 204:4047. https://doi.org/10.1016/j.micRes2017.07.004

267. Niu Y, Wu J, Wang W, Chen Q (2019) Production and characterization of a new glycolipid, mannosylerythritol lipid, from waste cooking oil biotransformation by Pseudozyma aphidis ZJUDM34. Food Sci Nutr 7:937-948. https://doi.org/10.1002/ fsn 3.880

268. Schaffer S, Wessel M, Thiessenhusen A (2014) Cells, nucleic acids, enzymes and use thereof, and methods for the Production of Sophorolipids-US 8.911.982 B2 https://www.lens.org/lens/ patent/127-281-411-967-478

269. Baccile N, Babonneau F, Banat IM, Ciesielska K, Cuvier A, Devreese B et al (2017) Development of a Cradle-to-Grave approach for acetylated acidic Sophorolipid biosurfactants. ACS Sustain Chem Eng 5:1186-1198. https://doi.org/10.1021/acssu schemeng.6b02570 
270. Saika A, Utashima Y, Koike H, Yamamoto S, Kishimoto T, Fukuoka T et al (2018) Biosynthesis of mono-acylated mannosylerythritol lipid in an acyltransferase gene-disrupted mutant of Pseudozyma tsukubaensis. Appl Microbiol Biotechnol 102:1759-1767. https://doi.org/10.1007/s00253-017-8698-2

271. Soetaert W, Van Bogaert I, Roelants S (2013) Methods to produce bolaamphiphilic glycolipids-WO 2015/028278 Al. https:// patents.google.com/patent/US20160168612A1/en

272. Van Renterghem L, Roelants SLKW, Baccile N, Uyttersprot K, Taelman MC, Everaert B et al (2018) From lab to market: An integrated bioprocess design approach for new-to-nature biosurfactants produced by Starmerella bombicola. Biotechnol Bioeng 115:1195-1206. https://doi.org/10.1002/bit.26539

273. Sallada ND, Harkins LE, Berger BW (2019) Effect of gene copy number and chaperone coexpression on recombinant hydrophobin HFBI biosurfactant production in Pichia pastoris. Biotechnol Bioeng 116:2029-2040. https://doi.org/10.1002/bit. 26982

274. Saika A, Koike H, Yamamoto S, Kishimoto T, Morita T (2017) Enhanced production of a diastereomer type of mannosylerythritol lipid-B by the basidiomycetous yeast Pseudozyma tsukubaensis expressing lipase genes from Pseudozyma antarctica. Appl Microbiol Biotechnol 101:8345-8352. https://doi.org/10.1007/ s00253-017-8589-6

275. Bahia FM, de Almeida GC, de Andrade LP, Campos CG, Queiroz LR, da Silva RLV et al (2018) Rhamnolipids production from sucrose by engineered Saccharomyces cerevisiae. Sci Rep 8:1-10. https://doi.org/10.1038/s41598-018-21230-2

276. Solaiman DKY, Liu Y, Moreau RA, Zerkowski JA (2014) Cloning, characterization, and heterologous expression of a novel glucosyltransferase gene from sophorolipid-producing Candida bombicola. Gene 540:46-53. https://doi.org/10.1016/j.gene. 2014.02.029

277. Yang L, Li Y, Zhang X, Liu T, Chen J, Wei L et al (2019) Metabolic profiling and flux distributions reveal a key role of acetylCoA in sophorolipid synthesis by Candida bombicola. BioChem Eng J 145:74-82. https://doi.org/10.1016/j.bej.2019.02.013

278. Weber A, May A, Tim Z, Gorak A (2012) Downstream processing of biosurfactants. Chem Eng Trans 27:115-120. https://doi. org/10.3303/CET1227020

279. Gusmão CAB, Rufino RD, Sarubbo LA (2010) Laboratory production and characterization of a new biosurfactant from Candida glabrata UCP1002 cultivated in vegetable fat waste applied to the removal of hydrophobic contaminant. World $\mathbf{J}$ Microbiol Biotechnol 26:1683-1692. https://doi.org/10.1007/ s11274-010-0346-2

280. Bhardwaj G, Cameotra SS, Chopra HK (2015) Isolation and purification of a new enamide biosurfactant from Fusarium proliferatum using rice-bran. RSC Adv 5:54783-54792. https://doi. org/10.1039/c5ra08017g

281. Marcelino PRF, da Silva VL, Philippini CJVZ, Contiero J, dos Santos JC, da Silva SS (2017) Biosurfactants produced by Scheffersomyces stipitis cultured in sugarcane bagasse hydrolysate as new green larvicides for the control of Aedes aegypti, a vector of neglected tropical diseases. PLoS ONE 12:1-16. https://doi. org/10.1371/journalpone.0187125

282. Shen L, Zhu J, Lu J, Gong Q, Jin M, Long X (2019) Isolation and purification of biosurfactant mannosylerythritol lipids from fermentation broth with methanol/water/n-hexane. Sep Purif Technol 219:1-8. https://doi.org/10.1016/j.seppur.2019.03.009

283. Wang H, Kaur G, To MH, Roelants SLKW, Patria RD, Soetaert $W$ et al (2020) Efficient in-situ separation design for long-term sophorolipids fermentation with high productivity. J Clean Prod 246:118995. https://doi.org/10.1016/j.jclepro.2019.118995

284. Dolman BM, Kaisermann C, Martin PJ, Winterburn JB (2017) Integrated sophorolipid production and gravity separation.
Process BioChem 54:162-171. https://doi.org/10.1016/j.procb io.2016.12.021

285. Winterburn JB, Russell AB, Martin PJ (2011) Integrated recirculating foam fractionation for the continuous recovery of biosurfactant from fermenters. BioChem Eng J 54:132-139. https:// doi.org/10.1016/j.bej.2011.02.011

286. Chen H-L, Chen Y-S, Juang R-S (2008) Flux decline and membrane cleaning in cross-flow ultrafiltration of treated fermentation broths for surfactin recovery. Sep Purif Technol 62:47-55. https://doi.org/10.1016/j.seppur.2007.12.015

287. Yang X, Zhu L, Xue C, Chen Y, Qu L, Lu W (2012) Recovery of purified lactonic sophorolipids by spontaneous crystallization during the fermentation of sugarcane molasses with Candida albicans O-13-1. Enzyme Microb Technol 51(6-7):348-353. https://doi.org/10.1016/j.enzmictec.2012.08.002

288. Wang H, Tsang CW, To MH, Kaur G, Roelants SLKW, Stevens CV et al (2020) Techno-economic evaluation of a biorefinery applying food waste for sophorolipid production - a case study for Hong Kong. Bioresour Technol 303:122852. https://doi.org/ 10.1016/j.biortech.2020.122852

289. Najmi Z, Ebrahimipour G, Franzetti A, Banat IM (2018) In situ downstream strategies for cost-effective bio/surfactant recovery. Biotechnol Appl BioChem 65:523-532. https://doi.org/10.1002/ bab.1641

290. Jauregi P, Kourmentza K (2019) Membrane bfiltration of Biosurfactants In: separation of functional molecules in Food by membrane technology, Elsevier, pp 79-112. https://doi.org/10. 1016/B978-0-12-815056-6.00003-6

291. Gartshore J, Lim YC, Cooper DG (2000) Quantitative analysis of biosurfactants using Fourier Transform Infrared (FT-IR ) spectroscopy. Biotechnol Lett 22:169-172. https://doi.org/10.1023/a: 1005670031432

292. Smyth TJP, Perfumo A, Marchant R, Banat IM (2010) Isolation and analysis of low molecular weight microbial Glycolipids In: handbook of hydrocarbon and lipid microbiology 3705-3724. https://doi.org/10.1007/978-3-540-77587-4

293. Silva SNRL, Farias CBB, Rufino RD, Luna JM, Sarubbo LA (2010) Glycerol as substrate for the production of biosurfactant by Pseudomonas aeruginosa UCP0992. Colloids Surfaces B Biointerfaces 79:174-183. https://doi.org/10.1016/j.colsurfb. 2010.03.050

294. Farias JM, Stamford TCM, Resende AHM, Aguiar JS, Rufino RD, Luna JM et al (2019) Mouthwash containing a biosurfactant and chitosan: an eco-sustainable option for the control of cariogenic microorganisms. Int J Biol Macromol 129:853-860

295. Resende AHM, Farias JM, Silva DDB, Rufino RD, Luna JM, Stamford TCM et al (2019) Application of biosurfactants and chitosan in toothpaste formulation. Coll Surf B Biointerfaces 181:77-84. https://doi.org/10.1016/j.colsurfb.2019.05.032

296. Freitas BG, Brito JGM, Brasileiro PPF, Rufino RD, Luna JM, Santos VA et al (2016) Formulation of a commercial biosurfactant for application as a dispersant of petroleum and by-products spilled in Oceans. Front Microbiol 7:1-9. https://doi.org/10. 3389/fmicb.2016.01646

297. Santos DKF, Resende AHM, de Almeida DG, Soares da Silva R, de CF, Rufino RD, Luna JM, et al (2017) Candida lipolytica UCP0988 biosurfactant: potential as a Bioremediation agent and in formulating a commercial related product. Front Microbiol 8:1-11. https://doi.org/10.3389/fmicb.2017.00767

298. Barcelos GS, Dias LC, Fernandes PL, Fernandes RDCR, Borges AC (2014) Spray drying as a strategy for biosurfactant recovery, concentration and storage. Springerplus 3:1-9. https://doi.org/ 10.1186/2193-1801-3-49

299. Campos JM, Stamford TLM, Sarubbo LA (2019) Characterization and application of a biosurfactant isolated from Candida 
utilis in salad dressings. Biodegradation 30(4):313-324. https:// doi.org/10.1007/s10532-019-09877-8

300. Campos JM, Stamford TLM, Rufino RD, Luna JM, Stamford TCM, Sarubbo LA (2015) Formulation of mayonnaise with the addition of a bioemulsifier isolated from Candida utilis. Toxicol Rep 2:1164-1170. https://doi.org/10.1016/j.toxrep.2015.08.009

301. Ceresa C, Fracchia L, Fedeli E, Porta C, Banat IM (2021) Recent advances in biomedical, therapeutic and pharmaceutical applications of microbial surfactants. Pharmaceutics 13:466. https://doi.org/10.3390/pharmaceutics13040466

Publisher's Note Springer Nature remains neutral with regard to jurisdictional claims in published maps and institutional affiliations. 